\title{
Review Article \\ Recent Progress in Processing of Tungsten Heavy Alloys
}

\author{
Y. Şahin \\ Department of Manufacturing Engineering, Faculty of Technology, Gazi University, Besevler, 06500 Ankara, Turkey \\ Correspondence should be addressed to Y. Şahin; yusufsahin1954@gmail.com
}

Received 16 August 2014; Revised 4 November 2014; Accepted 4 November 2014; Published 29 December 2014

Academic Editor: Thierry Barriere

Copyright (C) 2014 Y. Şahin. This is an open access article distributed under the Creative Commons Attribution License, which permits unrestricted use, distribution, and reproduction in any medium, provided the original work is properly cited.

\begin{abstract}
Tungsten heavy alloys (WHAs) belong to a group of two-phase composites, based on W-Ni-Cu and W-Ni-Fe alloys. Due to their combinations of high density, strength, and ductility, WHAs are used as radiation shields, vibration dampers, kinetic energy penetrators and heavy-duty electrical contacts. This paper presents recent progresses in processing, microstructure, and mechanical properties of WHAs. Various processing techniques for the fabrication of WHAs such as conventional powder metallurgy (PM), advent of powder injection molding (PIM), high-energy ball milling (MA), microwave sintering (MW), and spark-plasma sintering (SPS) are reviewed for alloys. This review reveals that key factors affecting the performance of WHAs are the microstructural factors such as tungsten and matrix composition, chemistry, shape, size and distributions of tungsten particles in matrix, and interface-bonding strength between the tungsten particle and matrix in addition to processing factors. SPS approach has a better performance than those of others, followed by extrusion process. Moreover, deformation behaviors of WHA penetrator and depleted uranium (DU) Ti alloy impacting at normal incidence both rigid and thick mild steel target are studied and modelled as elastic thermoviscoplastic. Height of the mushroomed region is smaller for $\alpha=0.3$ and it forms sooner in each penetrator as compared to that for $\alpha=0.2$.
\end{abstract}

\section{Introduction}

The name of "tungsten" is derived from the Swedish term meaning "heavy stone." Tungsten has been assigned the chemical symbol $\mathrm{W}$ after its German name wolfram. Tungsten, the metal with the highest meting point $\left(3422^{\circ} \mathrm{C}\right)$, has many advantages, such as high temperature strength, high creep resistance and high thermal conductivity, high electric resistance, the lowest vapor pressure, and the lowest coefficient of thermal expansion. These properties make tungsten a premium candidate for high temperature applications like, for example, in fusion reactor [1]. Another important industrial property of tungsten is its high density of $19.3 \mathrm{~g} / \mathrm{cm}^{3}$, which makes it an ideal material for shielding or collimating energetic $\alpha$ - and $\gamma$-radiation. The disadvantage of tungsten, however, is its inherent brittleness because tungsten has a transition from brittle to ductile fracture. Its treatment is realized at temperatures that are higher than brittleness limit. This temperature varies for commercially pure tungsten (99.95\%) in the interval between 300 and $400^{\circ} \mathrm{C}$, in case of recrystallized tungsten around $500^{\circ} \mathrm{C}$. Undesirable mixtures such as oxygen, nitrogen, and carbon significantly influence mechanical and physical properties of pure tungsten. They mainly precipitate at the grain boundaries in the form of oxides, nitrides, and carbides [2]. It is possible to reduce the transition temperature of pure tungsten by rotary sawing at temperatures $1550-1450^{\circ} \mathrm{C}$, transition temperature drops at $150^{\circ} \mathrm{C}$. Tungsten's strength and plastic characteristics increase with making the tungsten alloy, which can be divided into three basic groups: (a) solid solution alloys, (b) heterogeneous alloys like dispersion-hardening alloys, and (c) precipitationhardening alloys. Alloying elements like $\mathrm{Nb}, \mathrm{Ta}, \mathrm{Mo}, \mathrm{Zr}$, $\mathrm{Rh}, \mathrm{B}, \mathrm{C}$, and others influence tungsten's strength properties and its plastic deformability. Pure tungsten has a bodycentered cubic (BCC) material whose single crystals are virtually elastically isotropic at low pressures. The major uses for pure tungsten are in wire form in electrical lamps and electronic vacuum tubes, glass-metal sealing rods, cathode materials, electrical contacts, and heating elements [3]. Tungsten powder with an average particle size from 0.5 to $40 \mu \mathrm{m}$ is 
used for producing tungsten carbide as cutting tools, milling tools, and mining drills. Furthermore, since the late 1960s, tungsten carbide has been considered as an anode material for hydrogen or methanol fuel cells $[4,5]$.

Tungsten heavy alloys (WHAs) are a typical class of twophase composites consisting of nearly spherical tungsten particles embedded in a ductile matrix phase with lower melting point elements such as nickel, iron, copper, and cobalt [6]. The spheroidized phase microstructure is essentially pure tungsten, which is surrounded by a metallic binder phase containing some dissolved tungsten particles over $80 \mathrm{wt} . \%$ [7]. WHAs have been processed through PM route for some specific applications like mechanical alloying and infiltration since 1980s [8]. These heavy alloys contain mainly pure tungsten as principal phase in association with a matrix phase containing transition metals. $\mathrm{Ni}$ to $\mathrm{Cu}$ ratio in the heavy alloys can range from 3.2 to 4.1. Price et al. [9] are the first to propose the $\mathrm{Ni}-\mathrm{Cu}$ as the binder for tungsten heavy alloys. Over the last several years, these alloys have been extensively investigated for densification mechanism and microstructural evaluation and properties [10, 11]. WHAs are usually fabricated by liquid-phase sintering (LPS) process from micronsized $\mathrm{W}-\mathrm{Ni}-\mathrm{Fe}$ or $\mathrm{W}-\mathrm{Ni}-\mathrm{Cu}$ elemental powder mixtures at a temperature above $1460^{\circ} \mathrm{C}$ [12]. During LPS, the nickel alloy melt, which has a high solubility for tungsten, dissolves the tungsten-tungsten bonds that are formed during solidstate sintering. When the solid bonds are penetrated, particle rearrangement and pour filling occur, resulting in rapid densification of the compact. Therefore, tungsten solubility and tungsten grain shapes retention are two main concerns in determining the mechanical properties of sintered heavy alloys. Use of prealloyed powder improves homogeneity. The homogenization process also accelerates sintering and promotes densification. Ramakrishnan and Upadhayaya [13] and Kuzmic [14] study the effects of composition, temperature, and rapid cooling on densification and microstructure of the heavy alloys. The heavy alloys can be produced in a variety of near-net shapes, but the most frequently encountered shapes are those of cylindrical rods. After sintering, the final microstructure consists of coarsened-large spherical BCC tungsten grains dispersed in FCC solidified matrix. The final tungsten grain size is typically about $20-60 \mu \mathrm{m}$ in diameter. The properties of LPS materials in general are degraded by prolonged final stage of sintering time. Hence, short sintering times are preferred in practice. However, the liquid-phase sintered WHAs are susceptible to distortion and slumming due to the large difference between tungsten and liquid matrix. Thus, understanding and controlling the microstructure evaluation in terms of composition, densification, processing like heating rate, solubility properties, and the structural rigidity are of great importance to materials engineers and scientists in the processing of WHAs.

Due to the outstanding combination of the properties related to body-centered cubic tungsten phase and face-centered cubic matrix, such as high physical and mechanical properties, such as high density $\left(16-18 \mathrm{~g} / \mathrm{cm}^{3}\right)$, high strength (1000-1700 MPa), and high ductility (10-30\%) [15], thermal conductivity, and good corrosion resistance, WHAs are widely used in radiation shields, counterbalance, vibration dampers, kinetic energy (KE) penetrators and rocket nozzles in space crafts [16-20]. The major disadvantage of WHAs is that they have a lesser penetration capability than depleted uranium alloys (DUs), which are another penetrator material [21]. The DUs show superior penetration performance because of self-sharpening behavior. WHAs, however, develop mushroom-like heads (blunt behavior) during penetration due to adiabatic shear deformation, which result in a lower penetration depth when compared to depleted uranium alloys. For penetrators, there are two key factors affecting the penetration ability which are good penetration and high density in addition to low heat capacity and low strain rate hardening $[8,21]$. So far, most investigators focused mainly on enhancement of the mechanical properties of WHAs in order to improve the penetration capabilities for kinetic energy penetration applications. For achievement of this purpose, several techniques are proposed including grain size control of $\mathrm{W}$, alloying elements like Mo, Re, solid state interring, mechanical alloying, cold working followed by recrystalline, cyclic heat treatment, and oxide dispersion strengthening and many useful experimental results have been obtained [17-24]. This paper reviews recent progress on the processing, microstructure, and mechanical properties of WHAs. In addition, the Johnson-Cook relation [25] and Zhou et al. [26] thermal softening function are reviewed to model the axisymmetric, elastic thermoviscoplastic deformations of DU and WHA rods penetrating a mild steel target.

\section{Processing Techniques}

As tungsten based materials are refractory materials, melting and casting of these materials are extremely difficult. Therefore alternative-processing techniques are required, which are discussed below.

2.1. Powder Metallurgy. Powder metallurgy (P/M) is a process, in which a material powder is compacted as a green body and sintered to a net shape at elevated temperature. The basic steps consist of blending or mixing of elemental/alloy WHAs powders (a), followed by compacting the mixture in a suitable die or mold (b), and heating the resulting green compacts in a controlled atmosphere furnace so as to bond the particles metallurgically (c); this heating process is called "sintering" [27]. The resulting parts are solid bodies of material with sufficient strength and density for use in diverse fields of applications. In some times, steeps (a) and (b) are combined, which is called "hot isostatic pressing," because the powder mix is subjected simultaneously to pressure and elevated temperature. The sintered parts may be subjected to one or more secondary finishing operations like grinding and plating. The first production of WHAs and tungsten carbide materials by $\mathrm{P} / \mathrm{M}$ method started in the early part of the last century. To obtain homogeneous distributions of rounded W solid phases in the alloy is important to tackle in the processing step. Solid solution alloy is produced when, for example, the element Re is added to a $93 \mathrm{~W}-4.9 \mathrm{Ni}-2.1 \mathrm{Fe}$ alloy, inhibiting tungsten grains from precipitation growth [28]. However, adding the element $\mathrm{Cr}$ causes the interphases with 
elements $\mathrm{W}, \mathrm{Ni}, \mathrm{Fe}$, and $\mathrm{O}$ to accumulate along interface alloy, resulting in lower mechanical properties of the alloys. Addition of Mo reduces the concentration of $\mathrm{W}$ in the liquid matrix phase during sintering and, consequently, fines the microstructure of alloys $[29,30]$. Former studies indicate the liability of forming a precipitated phase with the addition of high concentration of Mo, which lead to brittleness of the alloy [31]. The coprecipitation of $\mathrm{W}, \mathrm{Mo}, \mathrm{Ni}$, and Fe results in the formation of an intermetallic phase at the interface like $\mathrm{W}_{4} \mathrm{Mo}$ and $\mathrm{Ni}_{7} \mathrm{Fe}$, which is in good agreement with the early work $[32,33]$. As $\mathrm{Mn} / \mathrm{Ni}$ ratio increases, $\mathrm{W}$ solubility in the matrix decreases due to the presence of $\mathrm{Mn}$ in matrix and causes refinement of $\mathrm{W}$ grains [34].

LPS at various temperatures [35-38] prepare microstructure and mechanical properties of WHAs with different compositions. All results are dependent on grain size, alloying content, compositions, and sintering time. The first two show increase in tensile properties and hardness in the presence of a finer $\mathrm{W}$ grain size. The tensile strength and elongation remarkably deteriorate at higher temperatures. The third indicates that both microstructure and mechanical properties are sensitively depending on alloy compositions, while the effect of varying $\mathrm{W}$ content significantly affects the microstructure of WHAs [38]. By increasing the Ni/Fe ratio, there is higher solubility for $\mathrm{W}$ in the matrix, giving a slightly larger grain size with a lower contiguity. The tensile strength and elongation are the highest for sintering times from 30 to $90 \mathrm{~min}$, reflecting a minimum in the residual porosity $[39,40]$. However, decreasing the yield strength with increasing sintering time is in agreement with the Hall-Petch behavior of 93W-4.9Ni-2.1Fe heavy alloy [41, 42]. Densification, microstructure, and mechanical properties of $90 \mathrm{~W}-4 \mathrm{Ni}-6 \mathrm{Mn}$ heavy alloys indicate that temperature most critically influences the microstructure because sintering density decreases rapidly with increasing temperature while temperature decreases with decreasing the grain size [43]. The grain coalescence and distortion are induced by prolonging the sintering time or elevating sintering temperature [44]. In comparison to $93 \mathrm{~W}-4.9 \mathrm{Ni}-2.1 \mathrm{Fe}$ alloy, $93 \mathrm{~W}-7(\mathrm{Ni}-\mathrm{Fe}-\mathrm{Mo})$ heavy alloy has a higher tensile strength and a better ductility [45]. Heating rate during sintering is another parameter that affects the densification and distortion. The grain growth rate constant varies inversely with the volume fraction of liquid to $2 / 3$ power [46]. The grain size, volume fraction of binding phase, and microhardness vary gradually due to the graded distribution of Mo [29]. The general trend is an increase in solid volume fraction, contiguity, and grain size with increasing $\mathrm{W}$ content $[47,48]$. The strength of the alloy increases significantly due to greater hardening of the matrix phase. The strength properties result in an embrittlement behavior with decreasing the temperature [49].

Deformation properties of WHAs are studied under different conditions; the strength of the alloy increases significantly due to a greater hardening of the matrix phase and $\mathrm{W}$ grains are elongated significantly after deformation mechanism [50]. However, strength and elongation of WHAs are deteriorated very rapidly when tested over $650^{\circ} \mathrm{C}$. The strength properties result in an embrittlement behavior with decreasing the temperature. The dynamic compression failure study indicates that shear band formation (ASB) is a failure mechanism for WHAs [51-53]. The microstructure evaluation of ASB formation is mainly based on the dynamic deformation process and the initial temperature [54-56]. ASB and penetration performance will be discussed within a more detailed way at the end of the mechanical behavior section. Powder metallurgy techniques can generally be classified into powder injection molding, mechanical alloying, microwave, and spark plasma sintering; these are discussed briefly in the following.

2.2. Powder Injection Molding. The powder injection molding (PIM) process is a combination of powder metallurgy and plastic injection molding technologies. This process offers three main advantages such as precise and reproducible components, complex shape, and high densification due to use of very fine ceramic or metal powders in the feedstock [57]. The process consists of mixing a small amount of organic polymer materials like wax polymer, polyacetal, and so forth with the desired inorganic powder, followed by granulation or pelletisation of the mixture [58]. The processing steps consist of feedstock preparation, injection molding, debinding, and consolidation [59]. The control of binder removal and maintaining its shape integrity are a challenge for the process. Unless the binder is removed gradually and the removal of the organic binder phase is completed, numerous defects can be formed when producing WHAs. The tensile properties are comparable to the conventional press and sinter alloys of a similar composition [60]. The solvent debinding temperature and thermal debinding atmosphere are found to be the principal factors affecting the mechanical properties of the alloy $[61,62]$. Effect of agglomerates with different contents on the green and sintered properties of $97 \mathrm{~W}-2.1 \mathrm{Ni}-0.9 \mathrm{Fe}$ heavy alloys for tensile specimens indicates that particle characteristics have no effect on the microstructure and mechanical properties because agglomeration remains as porous structure in the molded green compacts $[63,64]$. The feedstock formed by mechanically alloyed (MAed) for $\mathrm{W}-\mathrm{Ni}-\mathrm{Fe}$ nanocrystalline composite powder and wax multicomponent binder has good flow ability and mold ability. $90 \mathrm{~W}-7 \mathrm{Ni}-3 \mathrm{Fe}$ composites by PIM are widely investigated [65-69] mainly due to unique combination of high density, high strength, good ductility, and corrosion resistance of these materials. Solid-state sintering in the range between 1350 and $1450^{\circ} \mathrm{C}$ [70] produces fully densified parts with high mechanical properties and negligible distortion. The results indicate that the ultimate tensile strength exhibits the highest value at a sintering temperature of $1500^{\circ} \mathrm{C}$ and an isothermal holding time of $40 \mathrm{~min}$ [71, 72]. Micropowder injection molding $(\mu \mathrm{PIM})$ is another new and fast-developing micromanufacturing technique for the production of metal and ceramic component.

2.3. High Energy Ball Milling. Mechanical alloying (MA), which represents a high-energy ball milling process, has established itself as a viable solid state-processing route for the synthesis of a variety of equilibrium and nonequilibrium phase mixtures. It was originally developed to produce oxidedispersion strengthened (ODS) nickel- and iron-base super 


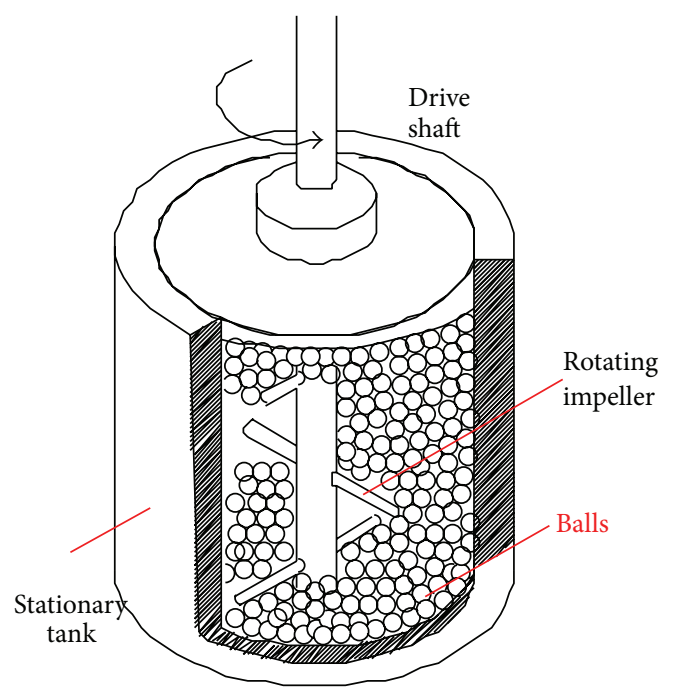

(a)

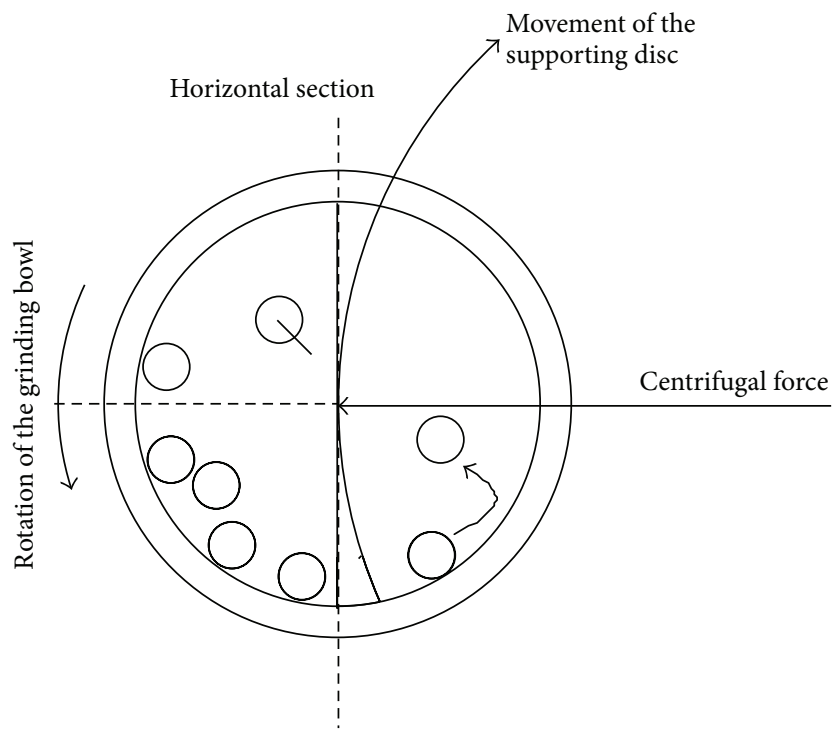

(c)

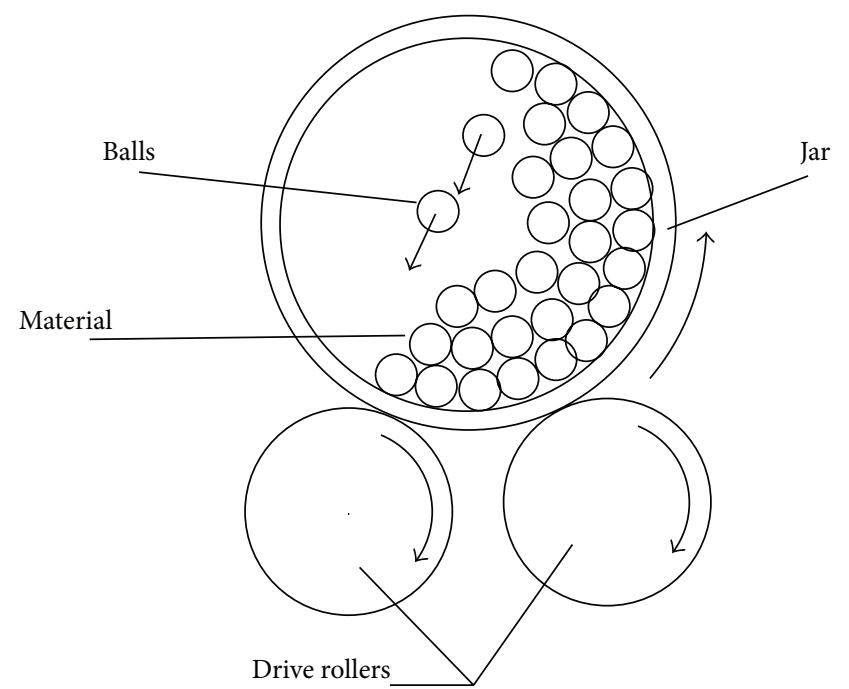

(b)

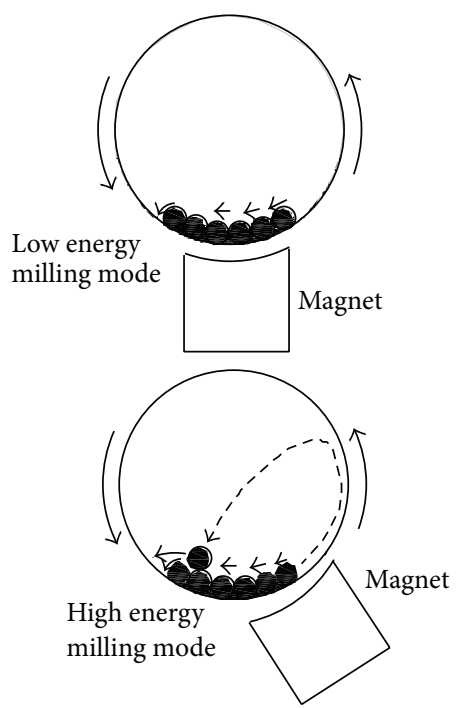

(d)

FIGURE 1: Schematic of ball movement in typical ball mills used for MA [75]. (a) Attritor, (b) tumbler mill, (c) planetary mill, and (d) uniball mill.

alloys for applications in aerospace industry. Benjamin [73] developed this technique around 1966. The powders are mixed in the mill along with the steel balls. This mix is then milled for the desired length of time until a steady state is reached. During this high-energy milling, the powder particles are repeatedly flattened, cold-welded, fractured, and rewelded [74]. Figure 1 shows the schematic ball movement in typical ball mills used for MA [75]. Among the laboratory mills, the SPEX shaker mills, which mill about $10 \pm 20 \mathrm{~g}$ of powder at a time, are most commonly used for alloy screening purposes. The energy transfer to the powder particles in these mills takes place by a shearing action or impact of the high velocity balls with the powder. This transfer is governed by many parameters such as type of mill, milling speed, type, size and size distribution of balls, ball/powder weight ratio, extent of filling of the vial, dry or wet milling, temperature of milling, atmosphere in the mill, and, finally, the duration of milling $[74,75]$. The mechanical alloying process of $93 \mathrm{~W}-$ $5.6 \mathrm{Ni}-1.4 \mathrm{Fe}$ tungsten heavy alloys shows that steady state stage is reached after milling for 48 hours and the grain size is refined to $16 \mu \mathrm{m}$ at the steady state stage. When solid-state sintered at $1300^{\circ} \mathrm{C}$ for $1 \mathrm{~h}$ in a hydrogen atmosphere, MAed WHA indicates ultrafine tungsten particles of about $3 \mu \mathrm{min}$ diameter with high density (above 99\%) [76]. These solidstate sintered WHAs with MA powders exhibit high yield strength of about $1100 \mathrm{MPa}$ due to a fine microstructure but show reduced elongation and impact energy mainly caused by a large area fraction of brittle W-W interface [77-79].

Figure 2 shows the SEM micrographs of two-stage sintered 93W-5.6Ni-1.4Fe WHA secondarily sintered at $1470^{\circ} \mathrm{C}$ 


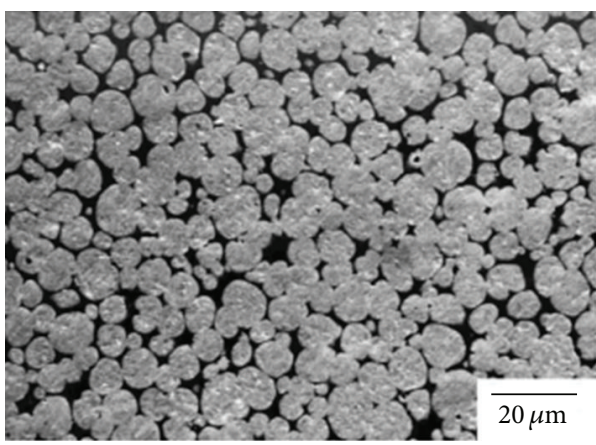

(a)

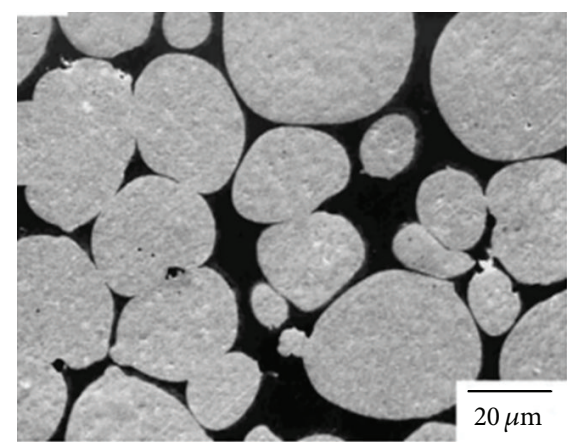

(b)

FIGURE 2: SEM micrograph of two-stage sintered $93 \mathrm{~W}-5.6 \mathrm{Ni}-1.4 \mathrm{Fe}$ WHAs secondarily sintered at $1470^{\circ} \mathrm{C}$ for (a) $4 \mathrm{~min}$ and (b) $90 \mathrm{~min}$ after solid-state sintering at $1300^{\circ} \mathrm{C}$ for $1 \mathrm{~h} \mathrm{[78]}$.

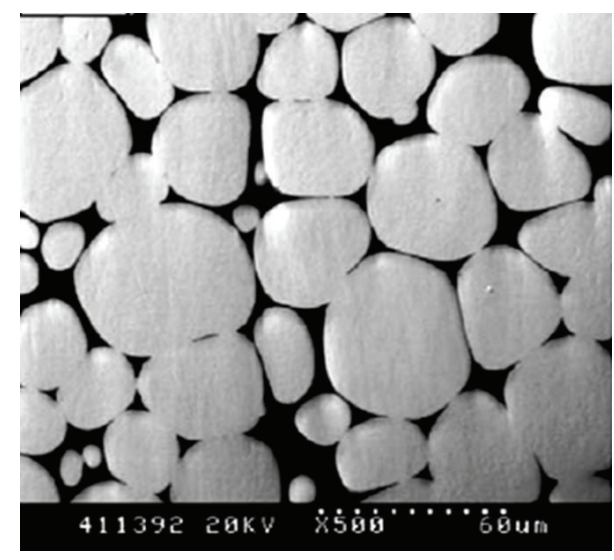

(a)

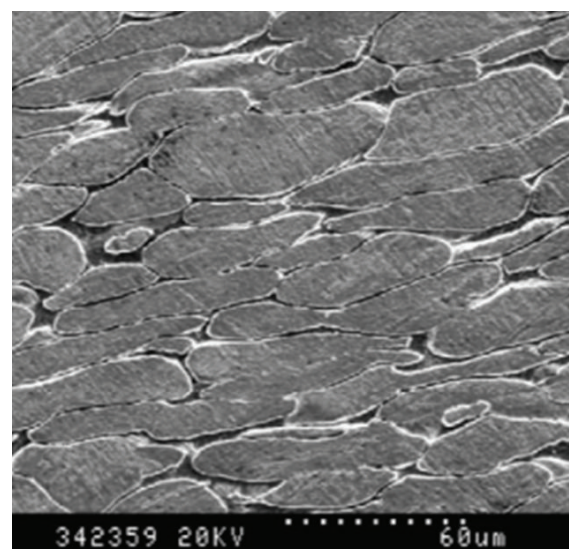

(b)

FIGURE 3: Longitudinal microstructure of $93 \mathrm{~W}-4.9 \mathrm{Ni}-2.1 \mathrm{Fe}$ alloy samples: (a) as-sintered and (b) hot hydrostatically extruded at an extrusion ratio of $2.86: 1$, respectively [92].

for $4 \mathrm{~min}$ and $90 \mathrm{~min}$ after solid-state sintering at $1300^{\circ} \mathrm{C}$ for $1 \mathrm{~h}$ [77]. The composition of $93 \mathrm{~W}-4.9 \mathrm{Ni}-2.1 \mathrm{Fe}$ alloy is mechanically alloyed (MAed) and nanocrystalline supersaturated solid solutions with grain size of $11 \mathrm{~nm}$ and amorphous phase are achieved during MA [80-83]. When sintered at $1150^{\circ} \mathrm{C}$ for $30 \mathrm{~min}$, the MAed powders show homogeneous microstructure and ultrafine tungsten particles of approximately $2 \mu \mathrm{m}$ with high density above $95 \%$. When $90 \mathrm{~W}-7 \mathrm{Ni}$ $3 \mathrm{Fe}$ nanocrystalline composite powder dispersed with $\mathrm{Y}_{2} \mathrm{O}_{3}$ addition fabricated by MA method, the maximum tensile strength obtained is $1050 \mathrm{MPa}$ and the elongation is 30\% [84]. Milling increases solubility of $\mathrm{W}$ in $\gamma$ phase and the solubility decreases with an increase of temperature [85]. 93W-3Ni$2 \mathrm{Fe}-2 \mathrm{Co}$ and $93 \mathrm{~W}-3.5 \mathrm{Ni}-1.5 \mathrm{Fe}-2 \mathrm{Copre}-$ alloyed powders with crystal cell size about $16 \mathrm{~nm}$ are synthesized by MA, and the hardness of these sintered WHA exhibits a trend with increasing sintering temperature and sintering time [86]. However, the nanosized powders by MA process exhibit that the average $\mathrm{W}$ grain size in the range of $1.7-3.0 \mu \mathrm{m}$ is obtained. The tensile strength more than $1200 \mathrm{MPa}$ is achieved at a sintering temperature of $1350^{\circ} \mathrm{C}$.
Significant improvements in mechanical properties of WHAs are achieved by hot extrusion, hot isostatic extrusion, and cold deformation, forged and swaging of compacts prepared from ball milled powder or powder mixtures [8790], but the last one indicates that the mechanical properties depend on the amount of deformation imparted during swaging. Rapid heat experiments of the order of seconds are performed on a $90 \mathrm{~W}-7 \mathrm{Ni}-3 \mathrm{Fe}$ alloy, which is cold worked by rotary swaging to 50 and $82 \%$ reduction in diameter [90]. Refined and elongated W grains into small round ones are obtained and increased deformation enhances the process of partition of W grains. Figure 3 shows a SEM micrograph of the longitudinal microstructure of the liquid-phase sintered and hot-hydrostatically extruded 93W-4.9Ni-2.1Fe alloy samples [91, 92]. W particles in the alloy are elongated along the extrusion direction. Figure 3(b) shows that the higher the average aspect ratio of the elongated $\mathrm{W}$ particles the bigger the extrusion ratio $(2.86: 1)$ used for hot-hydrostatic extrusion (Figure 3(b)). The ultimate tensile strength and hardness of the alloy were enhanced significantly and the increment in tensile strength and hardness is in proportion to the extrusion ratio [92]. 


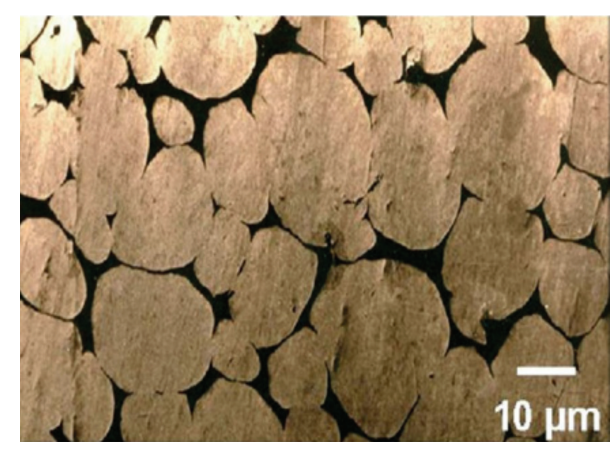

(a)

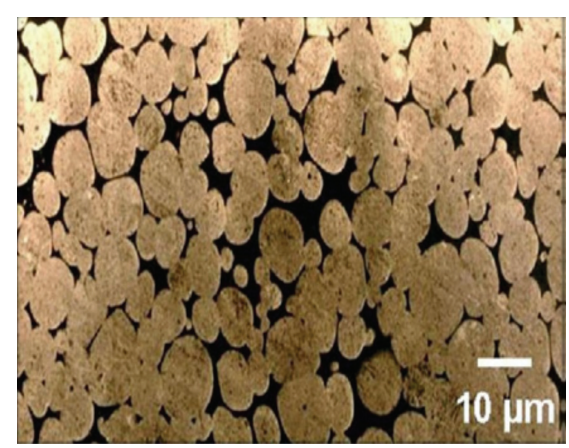

(b)

Figure 4: SEM micrographs of (a) CS and (b) MW-sintered 92.5W-6.4Ni-1.1Fe alloy [97].

2.4. Microwave Sintering Method. Microwave (MW) heating is a process in which the materials couple with microwaves, absorb the electromagnetic energy volumetrically, and transform into heat [93]. Microwaves directly interact with particulates within the pressed compacts rather than being conducted into the specimen from an external heat source, thereby providing rapid volumetric heating [94]. The sintering behavior of $92.5 \mathrm{~W}-6.4 \mathrm{Ni}-1.1 \mathrm{Fe}$ compacts consolidated in MW furnace and in conventional furnace (CF) indicates that no intermetallic phase formation occurs during MW processing [95]. MW sintered W-Ni-Fe microstructure shows significantly lower coarsening of $\mathrm{W}$ grains. The effect of heating rate on MW sintered $90 \mathrm{~W}-7 \mathrm{Ni}-3 \mathrm{Fe}$ heavy alloys exhibits excellent properties with the relative density over 99\% [96]. With increasing the heating rate, $\mathrm{W}$ grain size decreases from 13.6 to $9.6 \mu \mathrm{m}$ while the $\mathrm{W}-\mathrm{W}$ contiguity increases from 0.25 to 0.35 . The heating rate of $80^{\circ} \mathrm{C} / \mathrm{min}$ results in the best combination of microstructure and mechanical performance. Sintering under optimized conditions leads to enhanced mechanical properties, namely, $1020 \mathrm{MPa}$ tensile strength and $21 \%$ elongation.

The sintering behavior of $90 \mathrm{~W}-7 \mathrm{Ni}-3 \mathrm{Fe}$ alloy compared with prealloyed 90W-PA $(\mathrm{Ni}-\mathrm{Cu})$ alloy in both $\mathrm{CF}$ and MW furnace, at various temperatures [97], shows that MW sintering requires about $80 \%$ less processing time than required by $\mathrm{CF}$ method. Additionally, MW sintering provides relatively fine microstructure and better mechanical properties and consumes much less energy than CF sintering. The microstructures of the differently sintered alloys are compared in Figure 4 [97]. Despite such fast heating rate, no micro- or macrocracking nor distortion is observed in MWsintered samples.

A comparison on mechanical properties of CF and MW sintered alloys shows that the CF method gives some advantages like average grain size, tensile strength, and hardness $[97,98]$. Average grain sizes are about 17.3 and $9.4 \mu \mathrm{m}$ for CF and MW samples. Tensile strengths for CF and MW are about 642, $805 \mathrm{MPa}$ while hardness is about 210, $295 \mathrm{HV}$ for CF and MW applications, respectively. It is observed that better grain distribution and lack of intermetallic phase formation result in better mechanical properties in MW sintered compacts $[99,100]$.

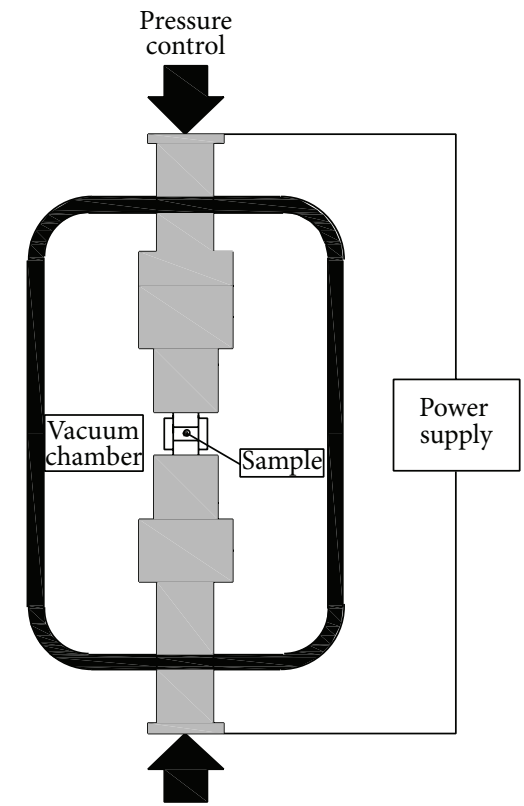

Figure 5: Schematic of the SPS process [101].

2.5. Spark Plasma Sintering. Spark plasma sintering (SPS) is a newly developed process, synthesis, and processing technique at low temperatures and short periods. The SPS process involves the sintering of powders under the simultaneous influence of current and pressure. In this process, powders are placed in a die (typically graphite). Heating is affected by passing a current (typically pulsed DC) through the die and the sample while a pressure is applied on the powder. The characteristics, therefore, include high heating rate, application of pressure, and effect of current [101]. Higher densification is obtained since powders are sintered under an applied pressure. The SPS process is schematically shown in Figure 5 [101]. It simultaneously applies an electric current along with mechanical pressure in order to consolidate powders or synthesize and simultaneously densify specific products.

However, the SPS technology has been successfully used to prepare WHAs within limited numbers [102-108]. Almost full densification is attained at $1250^{\circ} \mathrm{C}$ to produce fine-grained 
90W-7Ni-3Fe heavy alloys with $\mathrm{W}$ grain sizes of less than $5 \mu \mathrm{m}$. During heating, the hardness of the alloy tends to first rise, reaching the maximum value of $72.2 \mathrm{HRA}$ at $1100^{\circ} \mathrm{C}$, and then goes down. The microstructure of the specimen after high energy MA and pulse plasma sintering (PPS) tends to form a structure with an average grain size of $\sim 500 \mathrm{~nm}$ at a sintering temperature of $1100^{\circ} \mathrm{C}$ [105-107]. The maximum mechanical properties up to $2500 \mathrm{MPa}$ for nano- and ultradispersed W-Ni-Fe (WNF) and W-Ni-Fe-Co (WNFC) alloys are obtained. However, the PPS at high temperature above $1050^{\circ} \mathrm{C}$ deteriorates the strength characteristics of the alloy. For the SPS alloyed specimen, oxide film elimination of powders may improve the binding strength of the interface [108]. According to the literature [109], by optimizing the sintering times of pulsed- and constant-currents on the milled W$4 \mathrm{Ni}-2 \mathrm{Co}-1 \mathrm{Fe}$ powders, the density, hardness, and transverse rupture strength of the sintered alloy reach $16.78 \mathrm{~g} / \mathrm{cm}^{3}$, HRA 84.3, and $968 \mathrm{MPa}$, respectively. Meanwhile, W grain growth in sintering is effectively inhibited, and full density is obtained at approximately $1230^{\circ} \mathrm{C}$ with 5 min holding time $[110,111]$. Moreover, the grain growth by the SPS method can be essentially prevented [112].

\section{Microstructures}

Microstructure is a signature of the material processing. The microstructure is characterized by variants like grain size, shape, distributions of each phase, interface between the solid grains and matrix, porosity, and pore size in addition to processing factors such as temperature, heating rate, and holding time.

3.1. Interfacial Characteristics. To obtain composites with the desired microstructures and properties, the interfacial reaction should be controlled through selecting an appropriate matrix alloy and controlling the process parameters like temperature and holding time correctly. Wettability is related to surface energies of the interacting species by Young's equation. The contact angle, $\theta$, is associated with the balance of three interfacial energies, $\gamma_{S V}, \gamma_{S L}$, and $\gamma_{L V}$, as follows:

$$
\operatorname{Cos} \theta=\frac{\gamma_{S V}-\gamma_{S L}}{\gamma_{L V}}
$$

where the subscripts $S, L$, and $V$ represent solid, liquid, and vapor, respectively. The contact angle is altered by factors that change solubility or surface chemistry. For example, the addition of Mo to TiC-Ni system decreases the contact angle from $30^{\circ}$ to $0^{\circ}[113]$. The gradual variation of Mo content results in gradients of interfacial tension [114]. A low-contact angle induces liquid spreading over the solid grains, providing a capillary attraction that helps densify the system while a highcontact angle indicates poor wetting, so the liquid retreats from the solid. This results in compact swelling and liquid extruding from pores. XRD observation reveals that bec solid solution $\mathrm{W}$ phase, $\mathrm{Fe}_{7} \mathrm{~W}_{6}$ intermetallic phase, and $\mathrm{Fe}-\mathrm{Ni}$ solid solution phase form after $1 \mathrm{~h}$ at different temperatures.

3.2. Grain Size. Grain size is usually reported as the number of grains per unit area. The yield strength of the alloy is related

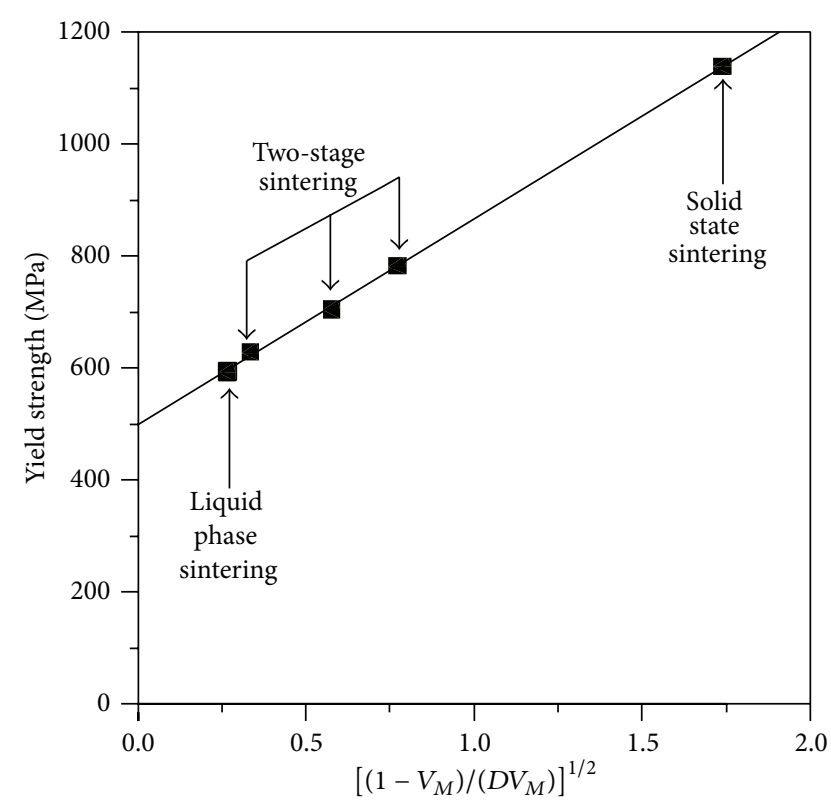

FIGURE 6: Variation of yield strength as a function of microstructural parameters including the matrix volume fraction, $V_{M}$, and tungsten particle size, $D$, of solid-state sintered, two-stage sintered, and liquid-phase sintered 93W-5.6Ni-1.4Fe WHAs [78].

to the inverse square root of its grain size, as shown by the Hall-Petch equation:

$$
\sigma_{y}=\sigma_{o}+K d^{-1 / 2}
$$

where $\sigma_{y}$ is the yield stress, $\sigma_{o}$ is the yield strength of a single crystal, $K$ is a constant, and $d$ is the grain size. Figure 6 shows that the yield strengths of WHAs are well represented as a function of $\left(1-V_{M} / D V_{M}\right)^{1 / 2}[78,79]$. These alloys exhibit a direct Hall-Petch relation above a crystallite size of $12 \mathrm{~nm}$ but an inverse Hall-Petch relation below $12 \mathrm{~nm}[43,83]$.

The grain size of crystalline $\mathrm{W}$ in powders decreases with increasing the milling times $[81,87,111,115]$. Increasing the milling times, amorphous transition takes place rapidly and the volume fraction of amorphous phase increases significantly [29]. Figure 7 shows the grain size of the MAed powders with increasing the milling time [82]. MA leads to a fast decrease of the grain size to less than about $11 \mathrm{~nm}$ after extended milling of $60 \mathrm{~h}$. In addition, the residual crystalline $\mathrm{W}$ decreases with the milling time.

The isothermal grain growth kinetics during LPS follows a simple power law:

$$
G^{n}-G_{o}^{n}=K t,
$$

where $G_{o}$ is the initial grain size, $G$ is the mean grain size, $t$ is the sintering time, and $K$ is the grain growth rate constant, which is related to the transport mechanism [23]. The mean grain volume increases linearly with time whereas the number of grains decreases with inverse time. The growth rate of $\mathrm{W}$ grain size drastically increases with annealing temperature higher than $1150^{\circ} \mathrm{C}$ [82]. The adding of Re and Mo prevents $\mathrm{W}$ atoms from solution-diffusion and inhibits 


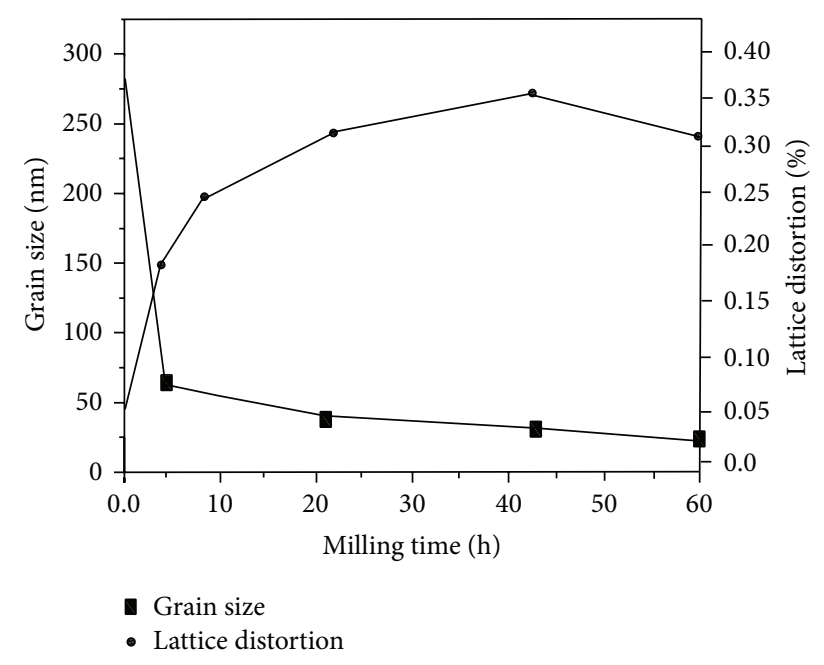

FIgURE 7: Variation of grain size and lattice distortion of tungsten versus milling time [82].

W grains from precipitation growth [78, 116, 117]. Nearly full density of $90 \mathrm{~W}-4 \mathrm{Ni}-6 \mathrm{Mn}$ alloys with sintering temperature in the $1100-1200^{\circ} \mathrm{C}$ range and ultimate tensile strength (UTS) of $1000 \mathrm{MPa}$ with a $25 \%$ elongation are achieved $[118,119]$. The capacity of atomic diffusion can be markedly improved by the thermal activation [14]. In most of WHAs systems, the solids content exceeds 60 vol. percentages.

3.3. Porosity and Pore Size. Pores are initially present as interparticle voids, but they might also arise from inhomogeneous particle packing or volatile phases in the green body like entrapment of gases, hydrogen production, and holding time. Porosity and inclusions are detrimental to the mechanical properties of heavy alloys. If the porosity is over $0.5 \%$, the properties of the materials, especially ductility, remarkably reduce [118-123]. As the smaller pores are filled, the mean pore size increases while the number of pores decreases. Compact swelling due to pore formation at prior particle sites is observed if the liquid forming particles have substantial solubility in the solid during heating $[124,125]$. However, swelling is reduced by the use of small melt-forming particles with a similar size as the interparticle voids. The reason for the swelling or bubbles is related to impurities and oxygen led by MA process. Another approach is to use a dry-wet hydrogen combination along with Ar to avoid gas pores and hydrogenembrittlement $[83,126]$. Since the grain size increases with sintering time, liquid filling of larger pores takes considerable time.

As for the case of the SPS, neck growth enhances by applying pressure and temperature [127-129]. The material plasticity increases substantially with decreasing the $\mathrm{W}$ content and the deformation capability being determined by the condition of the W-W and W-matrix zone interface [130]. As the solid content increases, a rapid increase in grain size is observed [47], but the larger grain size clearly indicates more rapid grain growth. The higher the contiguity with weak cohesive strength between the contacting grains, the poorer the mechanical properties [131]. The contiguity increases with increasing the heating rate because it causes more contacts between grains [122]. The contiguity decreases as the volume fraction of liquid phase increases.

\section{Mechanical Properties}

Strength and stiffness are the two most important characteristics among the mechanical properties. Furthermore, yield strength, hardness, creep resistance, fatigue, and even wear resistance are decisive for structural applications. These properties can be improved or deteriorated with many factors such as alloying, composition, heat treatment, adding reinforcement, methods, production parameters, and environment. When considering WHAs, the most effective factors determining the properties are individual constituents, volume fraction of reinforcement and matrix phase, distributions of solid particles, particle size and shape, interface bonding, and microstructural factors [127-134].

4.1. Tensile Strength and Hardness. Mechanical properties are essentially functions of manufacturing processes. Both tensile hardness and elastic modulus increase with introducing the reinforcement phase and its distribution, grain size, volume fraction, matrix content, heat treatment, and production type [129]. Particle strengthening, work hardening, load transfer from particle to matrix, grain size, and uniform distributions are the key strengthening mechanisms in WHAs. For example, the dispersion of hard and fine particles in the heavy alloy drastically blocks the motion of dislocations and therefore strengthens the matrix material. Work hardening also occurs when the composite strained since the higher density of dislocation in the matrix usually took place due to the strain mismatch between the particle and matrix, thus strengthening the material [130]. In addition, load transfer is very important strengthening mechanism. The applied stress can be transferred from the soft matrix to the particle phase if the interface bonding between the hard particle and matrix is strong enough. The room-temperature tensile properties of the as-swaged tungsten alloy samples show that the ultimate tensile strength of the alloy increases significantly (Figure 8). The ultimate tensile strength increases from $750 \mathrm{MPa}$ for sintered to $1640 \mathrm{MPa}$ for $75 \%$ swaged alloy [90].

The percent elongation to failure decreases from $20 \%$ to $6 \%$ that again can be attributed to strain hardening of both $\mathrm{W}$ and matrix phases. A fine-grained $90 \mathrm{~W}-7 \mathrm{Ni}-3 \mathrm{Fe}$ alloy with high tensile strength and elongation properties is obtained, with the maximum tensile strength of $1050 \mathrm{MPa}$ and elongation of $30 \%$. In addition, the hardness for $93 \mathrm{~W}-4.9 \mathrm{Ni}-2.1 \mathrm{Fe}$ and $93 \mathrm{~W}-4.9 \mathrm{Ni}-2.1 \mathrm{Fe}-0.03 \mathrm{Y}$ compact significantly increases with the increase in the temperature $[36,78,83]$. The maximum hardness increased up to HV $439 \pm 25$ for $93 \mathrm{~W}-$ 4.9Ni-2.1Fe alloy and HV $482 \pm 5$ for $93 \mathrm{~W}-4.9 \mathrm{Ni}-2.1 \mathrm{Fe}-0.03 \mathrm{Y}$ alloy after sintering at $1410^{\circ} \mathrm{C}$ for $1 \mathrm{~h}$. Table 1 shows some mechanical and physical properties of WHAs after sintering, extruding, and heat treatment. This table shows that sintering temperature, time, composition and alloying element, milling time, method applied, and environment are the main influencing factors on microstructure and mechanical properties of heavy alloys. Among these parameters, with increasing the 


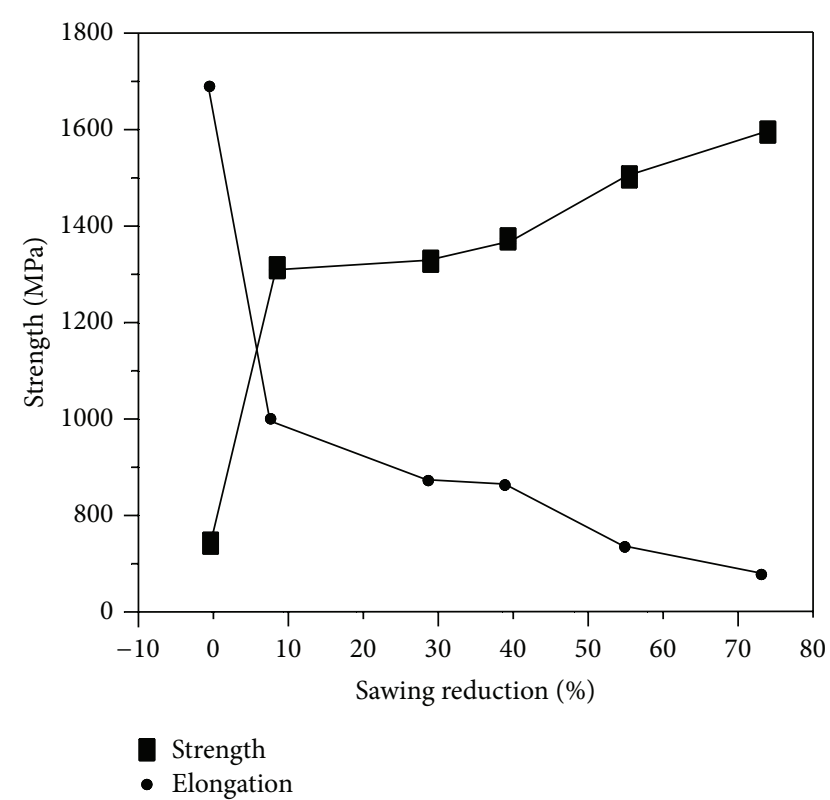

FIGURE 8: Variation of the strength and elongation with the swaging reduction [90].

milling time, its grain size decreases considerably. Thus, it leads to the improvement of the tensile and hardness of these samples at room temperature. Furthermore, novel production techniques like SPS extrusion provide some advantages over the other methods. The SPS method is found to have higher yield strength than the others. The higher tensile strength is combined with approximately $24 \%$ elongation. However, extrusion method also enhances the mechanical properties significantly because of the high aspect ratio of the elongated W particles during this process, followed by twostage MA sintered samples.

Improvements of the tensile strengths in SPS and extrusions are about $51 \%$ and $40.6 \%$, respectively. However, this reaches up to $47 \%$ when the extrusion ratio increases to $75 \%$. For the MW heating, 13\% improvements are achieved when compares to conventional one. In the case of conventional sintered samples associated with different compositions and temperature/times, 38\% improvements are obtained for the tensile strength while the elongation is lower than $21 \%$. As a result, development of method is found to be more effective on improvements of mechanical properties of WHAs than those of other parameters.

4.2. Fracture Surfaces. It is observed that there are four possible fracture paths for WHAs microstructure: matrix failure, $\mathrm{W}$ cleavage, $\mathrm{W}$-W intergranular failure, and $\mathrm{W}$-matrix interfacial separation [131]. The most fractured interfaces are composed of $\mathrm{W}-\mathrm{W}$ interface boundaries in solid-state sintered 93W-5.6Ni-1.4Fe WHA and two-stage sintered 93W5.6Ni-1.4Fe WHA [115]. Failure under tension starts by separation of W-W interface areas and develops by producing cleaved $\mathrm{W}$ grains after strain hardening of the matrix phase. However, at the same time, the ductility of the alloy decreases as W content increases, and above $93 \% \mathrm{~W}$ the ductility of the alloys decreases drastically. The strength of WHAs increases as the fracture surface changes from flat facets, river like, to sheared W grains [90]. Lower strength and ductility in 90W$6 \mathrm{Ni}-2 \mathrm{Fe}-0.5 \mathrm{Co}-1.5 \mathrm{Mo}$ alloy are attributed to the presence of a higher fraction of flat faceted $\mathrm{W}$ grains. Oxides at W-W and $\mathrm{W}$-matrix interface severely promote fracture and thus elongation decreases $[80,83]$. However, the fracture surface by impact test reveals a change of the W-W interface failure mechanism towards ductile failure of penetrated matrix with many dimples by increasing the matrix penetration $[43,50]$.

The microstructure and processing factors of the heavy alloys are the key to affect their mechanical properties. For WHAs, the main influencing factors of mechanical properties include compositions [27-33,36-39, 83], processing type [71$73,85,95,99,103,122,132,133]$ and temperature/time $[41,43$, $62,76,86,97,104,105,134]$, tungsten grain size and shape effect $[47,81,87,118]$, grain growth $[46,82,110,112,117]$, interface bonding between $\mathrm{W}$ and matrix $[80,90,114,130,131]$, and porosity and pore size distribution $[49,83,118,124,125,127]$.

4.3. Penetrator Performance. In order to increase the penetration performance it is desirable to promote adiabatic shear banding localized to small areas and at higher shear strains. For WHAs, first, W/W interfacial area without altering W content should be reduced. Secondly, the W grain size should be increased and thus contiguity decreases. Thirdly, the coated powder should be used. Table 2 indicates requirements of an ideal KE penetrator. Among all types of penetrator materials, there are two key factors affecting the penetration ability, which are good penetration and high density [135].

Traditionally, depleted uranium (DU) alloys U-3/4Ti are used as penetrators in all cannon-fired KE projectiles. However, due to environmental issue and health hazardous of DU, there is a drive to replace DU alloys by alternative materials. The development of a large mushroomed head on the penetrator is observed for pure tungsten, WHAs, and a uranium-6\% niobium alloy is shown in Figure $9[135,136]$.

However, other U-3/4Ti alloy penetrators, which rapidly develop localized adiabatic shear failure, create smaller diameter penetrator cavities than WHAs penetrators. This type of failure results in a chiseled head formation (self-sharpening effect), which improves KE penetrators performance. As stated above, the former indicates self-sharpening effect, whereas the latter shows a mushrooming effect. This is the fact that the very high melting of $\mathrm{W}$ entails a low thermal softening associated with high rate sensitivity of $\mathrm{W}$ with the strength increasing with an increasing strain-rate. These effects delay flow softening at high strain rates. Because of delaying onset of shear stress localization, WHAs develop "mushroom heads" during penetration.

WHAs such as the one studied here have been studied extensively, primarily as potential materials for KE projectiles [136]. Mechanical properties and physical phenomena at high strain rates have been obtained or observed using Hopkinson bar techniques [137], normal plate impact [138140], and oblique flyer-plate impact [141]. In most of these, the bulk mechanical properties of the homogenized multiphase material (e.g., stress-strain curves and spall strengths) and microstructure such as fracture surfaces or shear localization initiation sites have been reported. 
TABLE 1: Some mechanical and physical properties of WHAs after sintering or heat treatment obtained from the literature.

\begin{tabular}{|c|c|c|c|c|c|c|c|}
\hline Composition (wt.\%) & Process & $\begin{array}{l}\text { Relative } \\
\text { density } \\
\left(\mathrm{g} / \mathrm{cm}^{3}\right)\end{array}$ & $\begin{array}{l}\text { Grain } \\
\text { size } \\
(\mu \mathrm{m})\end{array}$ & $\begin{array}{l}\text { Tensile } \\
\text { strength or } \\
\text { compr. } \\
\text { strength } \\
(\mathrm{MPa})\end{array}$ & Elong. (\%) & $\begin{array}{l}\text { Hardness } \\
(\mathrm{HRC} / \mathrm{HV})\end{array}$ & Reference \\
\hline $90 \mathrm{~W}-7 \mathrm{Ni}-3 \mathrm{Fe}(1)$ & As-sintered (1); & 99.7 & \multirow{4}{*}{-} & 890 & 25 & 27 & \multirow{4}{*}[6]{} \\
\hline $90 \mathrm{~W}-7 \mathrm{Ni}-3 \mathrm{Fe}(2)$ & As-extruded (2); & 99.7 & & 1260 & 10 & 36 & \\
\hline $93 \mathrm{~W}-4.9 \mathrm{Ni}-2.1 \mathrm{Fe}(3) ;$ & As-sintered (3); & - & & 935 & 21 & 28 & \\
\hline $93 \mathrm{~W}-4.9 \mathrm{Ni}-2.1 \mathrm{Fe}(4)$ & As-extruded (4) & - & & 1390 & 7 & 39 & \\
\hline $\begin{array}{l}\text { 90.5W-7.2Ni-1.8Fe-0.5Co } \\
0.05 \mathrm{Mo}(1) ;\end{array}$ & As-sintered (1); & 99.4 & $25-50$ & 950 & 21 & 33 & \multirow{3}{*}[35]{} \\
\hline $92.5 \mathrm{~W}-5 \mathrm{Ni}-2.5 \mathrm{Cu}(2)$ & As-sintered (2); & 99.4 & 30 & 681 & 6 & 30 & \\
\hline 93.5W-4.0Ni-2Fe-0.5Co (3) & As-sintered (3) & 99.4 & 30 & 853 & 14 & 31 & \\
\hline $95 \mathrm{~W}-3.5 \mathrm{Ni}-1.5 \mathrm{Cu}(1)$ & As-sintered (1); & 98.4 & 60 & 660 & 3 & $450 \mathrm{HV}$ & \multirow{2}{*}[36]{} \\
\hline 91W-7Ni-1.5Fe-0.5Co (2) & As-sintered (2) & 99.4 & 30 & 1000 & 20 & $433 \mathrm{HV}$ & \\
\hline \multirow{3}{*}{$93 \mathrm{~W}-4.9 \mathrm{Ni}-2.1 \mathrm{Fe}-0.03 \mathrm{Y}$} & As-sintered-fine (1); & & 10 & 995 & 24 & 29 & \multirow{3}{*}[36]{} \\
\hline & As-extruded $(3.33: 1)(2)$; & - & 10 & 1570 & 6.5 & 48 & \\
\hline & As-sintered (3) & & 45 & 960 & 23 & 29 & \\
\hline \multirow{4}{*}{$95 \mathrm{~W}-3.5 \mathrm{Ni}-1.5 \mathrm{Fe}$} & As-sintered at $30 \mathrm{~min}(1)$ & & 18 & 930 & 18.2 & \multirow{4}{*}{-} & \multirow{4}{*}[41]{} \\
\hline & As-sintered at $90 \mathrm{~min}(2)$ & - & 30 & 940 & 22 & & \\
\hline & As-sintered at $240 \mathrm{~min}(3)$; & & 41 & 920 & 17.9 & & \\
\hline & As sintered at $640 \mathrm{~min}(4)$ & & 45 & 836 & 14 & & \\
\hline $97 \mathrm{~W}-2.1 \mathrm{Ni}-0.9 \mathrm{Fe}$ & As-sintered & 99.4 & 19 & 872 & 21.6 & - & {$[65]$} \\
\hline 88W-8.4Ni-3.6Fe-UDP; & As-sintered-MA (1); & 97.0 & 5 & 894 & 30 & - & \multirow{3}{*}[79]{} \\
\hline $93 \mathrm{~W}-4.9 \mathrm{Ni}-2.1 \mathrm{Fe}$ & As-sintered (2); & - & - & 996 & 23 & - & \\
\hline $\begin{array}{l}93 \mathrm{~W}-(6-x)(\mathrm{Ni}, \mathrm{Fe}) \mathrm{XPSZ} \\
\mathrm{Ni} / \mathrm{Fe}=4, \mathrm{X}=0.05\end{array}$ & $\begin{array}{c}\text { As-sintered and MA at } \\
300 \mathrm{MPa}(3)\end{array}$ & 99 & 22 & $\begin{array}{c}340-425 \\
\left(800^{\circ} \mathrm{C} \text { comp. }\right. \\
\text { YS }) \\
\end{array}$ & - & - & \\
\hline $93 \mathrm{~W}-4.9 \mathrm{Ni}-2.1 \mathrm{Fe}(1)$ & $\begin{array}{l}\text { As-sintered at } 1300^{\circ} \mathrm{C} \text { for } \\
60 \mathrm{~min}(1) ;\end{array}$ & 99.6 & 38 & - & - & $438 \mathrm{HV}$ & \multirow{7}{*}[92]{} \\
\hline $93 \mathrm{~W}-4.9 \mathrm{Ni}-2.1 \mathrm{Fe}-0.03 \mathrm{Y}(2)$ & $\begin{array}{c}\text { As-sintered at } 1410^{\circ} \mathrm{C} \text { for } \\
60 \min (2)\end{array}$ & 98.0 & 6 & - & - & $489 \mathrm{HV}$ & \\
\hline $94 \mathrm{~W}-4.8 \mathrm{Ni}-1.2 \mathrm{Fe}(3)$ & & 99.0 & 22 & 920 & 22 & & \\
\hline $\begin{array}{l}94 \mathrm{~W}-4.7 \mathrm{Ni}-1.18 \mathrm{Fe}-0.1 \mathrm{PSZ}(4) \\
94 \mathrm{~W}-4.56 \mathrm{Ni}-1.14 \mathrm{Fe}-0.3 \mathrm{PSZ}\end{array}$ & & & - & 925 & 9 & & \\
\hline \multirow{3}{*}{$93 \mathrm{~W}-4.9 \mathrm{Ni}-2.1 \mathrm{Fe}$} & As-sintered (1); & 99.7 & 4 & 960 & 23 & 28 & \\
\hline & As-sawed (2.5:1); & & - & 1300 & 15.2 & 42,43 & \\
\hline & As-sawed $(4: 1)$ & & - & 1540 & 9.2 & 48,49 & \\
\hline \multirow{2}{*}{$92.5 \mathrm{~W}-6.4 \mathrm{Ni}-1.1 \mathrm{Fe}$} & Conventional heating (1); & 98.5 & 17 & 642 & 3.5 & $210 / 398$ & \multirow{2}{*}[97]{} \\
\hline & MW heating (2) & 98.5 & 9.4 & 805 & 11.2 & $295 / 407$ & \\
\hline \multirow{4}{*}{$90 \mathrm{~W}-7 \mathrm{Ni}-3 \mathrm{Fe}$} & Conventional heating (1); & $5^{\circ} / \mathrm{min}$ & - & 862 & 19.7 & \multirow{4}{*}{-} & \multirow{4}{*}[98]{} \\
\hline & Conventional heating (2); & $10^{\circ} / \mathrm{min}$ & 20 & 817 & 12.8 & & \\
\hline & MW heating (3); & $45^{\circ} / \mathrm{min}$ & - & 898 & 20 & & \\
\hline & MW heating (4) & $105^{\circ} / \mathrm{min}$ & - & 850 & 21 & & \\
\hline $\begin{array}{l}95 \mathrm{~W}-3.5 \mathrm{Ni}-1.5 \mathrm{Fe}-\mathrm{UDP} \text { at } \\
200-1500^{\circ} \mathrm{C}(1) ;\end{array}$ & Free sintering (1); & 98 & $5-10$ & 1300 (YS) & $23>10$ & \multirow{3}{*}{-} & \multirow{3}{*}[104]{} \\
\hline PPS in $900-1300^{\circ} \mathrm{C}(2)$; & PPS sintering (2), & 98.5 & - & 1900 (YS) & settle & & \\
\hline Vacuum (3) & vacuum (3) & - & - & 2500 (YS) & $<0.2 \mathrm{~s}$ & & \\
\hline
\end{tabular}


TABle 1: Continued.

\begin{tabular}{|c|c|c|c|c|c|c|c|}
\hline Composition (wt.\%) & Process & $\begin{array}{l}\text { Relative } \\
\text { density } \\
\left(\mathrm{g} / \mathrm{cm}^{3}\right)\end{array}$ & $\begin{array}{l}\text { Grain } \\
\text { size } \\
(\mu \mathrm{m})\end{array}$ & $\begin{array}{l}\text { Tensile } \\
\text { strength or } \\
\text { compr. } \\
\text { strength } \\
(\mathrm{MPa})\end{array}$ & Elong. (\%) & $\begin{array}{l}\text { Hardness } \\
(\mathrm{HRC} / \mathrm{HV})\end{array}$ & Reference \\
\hline $90 \mathrm{~W}-4 \mathrm{Ni}-6 \mathrm{Mn}(1)$ & As-sintered (1); & 99.7 & 8 & $1030-1062$ & 25 & 32 & \\
\hline $93 \mathrm{~W}-5.6 \mathrm{Ni}-1.4 \mathrm{Fe}(2)$; & Blended-SPS (2); & 95 & 6 & $600-800(Y S)$ & - & - & \\
\hline $93 \mathrm{~W}-5.6 \mathrm{Ni}-1.4 \mathrm{Fe}(3)$; & $\begin{array}{c}\mathrm{MA} / \mathrm{SPS}, 1300^{\circ} \mathrm{C}, 1 \mathrm{~h} / 1470^{\circ} \mathrm{C} \text {, } \\
4-90 \mathrm{~min} \text { heat-treated, } 1150^{\circ} \mathrm{C} \text {, } \\
\text { WQ (3); }\end{array}$ & 99 & $6-27$ & 716 (TS) & - & - & {$[105]$} \\
\hline 91W-7Ni-1.5Fe-0.5Co (4) & $\begin{array}{c}\text { CIPed, } 250 \mathrm{MPa}, 1100^{\circ} \mathrm{C} \\
\text { followed by WQ (4) }\end{array}$ & 99.4 & 30 & - & - & - & \\
\hline $95 \mathrm{~W}-5(\mathrm{Ni} / \mathrm{Fe}=7 / 3)$ & As-sintered condition & - & - & 991 & 14 & - & {$[115]$} \\
\hline \multirow{7}{*}{$90 \mathrm{~W}-6 \mathrm{Ni}-2 \mathrm{Fe}-2 \mathrm{Co}$} & As-sintered- $1450^{\circ} \mathrm{C}, 2 \mathrm{~h}(1)$; & 99.6 & 6 & 450 & 5 & $430 \mathrm{HV}$ & \multirow{7}{*}[122]{} \\
\hline & $1150^{\circ} \mathrm{C} / 5 \mathrm{~h}(2)$ & & - & 750 & 18 & 435 & \\
\hline & W1-10\% (3); & & - & 1348 & 10 & 490 & \\
\hline & W3-40\% (4); & & - & 1430 & 9 & 530 & \\
\hline & W5-75\% (5); & & \multirow[t]{3}{*}{-} & 1646 & 6 & 610 & \\
\hline & $\mathrm{W} 4-700^{\circ} \mathrm{C}(6)$ & & & 1450 & 7 & 520 & \\
\hline & $\mathrm{W} 4-1100^{\circ} \mathrm{C}(7)$ & & & 1025 & 5 & 495 & \\
\hline $90 \mathrm{~W}-7 \mathrm{Ni}-3 \mathrm{Fe}$ & $\begin{array}{c}\text { As-sintered at } 1300-1400^{\circ} \mathrm{C} \\
(\mathrm{MA})\end{array}$ & 99.7 & $3-1.7$ & 1100 & Very low & 34 & {$[131]$} \\
\hline 88W-8.4Ni-3.6Fe (1); & As-sintered (1); & 99.00 & 3 & 894 & 30 & - & \\
\hline $93 \mathrm{~W}-4.9 \mathrm{Ni}-2.1 \mathrm{Fe}(2)$ & As-sintered (2); & - & - & 900 & 23 & - & {$[132]$} \\
\hline $90 \mathrm{~W}-7 \mathrm{Ni}-3 \mathrm{Fe}(3)$ & As-sintered (3) & 99.6 & & 1000 & 30 & - & \\
\hline $90 \mathrm{~W}-7 \mathrm{Ni}-3 \mathrm{Fe}-0.04 \mathrm{Y}_{2} \mathrm{O}_{3}$ & $\begin{array}{l}\text { As-sintered at } 1480^{\circ} \mathrm{C} \text { for } \\
30 \mathrm{~min} \\
\end{array}$ & - & 99.3 & 1050 & 30.8 & - & {$[133]$} \\
\hline \multirow{2}{*}{$93 \mathrm{~W}-4.9 \mathrm{Ni}-2.1 \mathrm{Fe}$} & As-sintered at $1530^{\circ} \mathrm{C}(1)$; & \multirow{2}{*}{-} & \multirow[t]{2}{*}{95} & 960 & 23 & 29 & \multirow{2}{*}[134]{} \\
\hline & As-extruded $(4: 1)(2)$ & & & 1540 & 9.2 & 48 & \\
\hline
\end{tabular}

TABLE 2: Requirements of an ideal KE penetrator.

\begin{tabular}{lcc}
\hline Number & Attribute & Function \\
\hline 1 & High density & Imparts high impact energy \\
2 & High strength & For greater heat generation for a given strain \\
3 & Low heat capacity & Heat generated results in rapid temperature rise \\
4 & Low work hardening rates & Easier flow softening \\
5 & Low strain rate hardening rate & Shear localization occurs at lower strain \\
6 & High thermal-softening rate & Shear banding initiated at lower temperature \\
\hline
\end{tabular}

The dynamic deformation and fracture behavior of an oxide $\left(0.1\right.$ wt. $\left.\% \mathrm{Y}_{2} \mathrm{O}_{3}\right)$ dispersed WHAs fabricated by MA show that interfacial bonding between $\mathrm{W}$ particles occurs over broad deformed areas in this alloy, suggesting the possibility of adiabatic shear banding (ASB) formation [18]. Combined dynamic compression and shear tests are carried out to study the deformation and failure behavior of pretwisted WHA at high strain rates of $10^{3} \mathrm{~s}^{-1}$ [54]. It is found that the initial microstructures such as the aspect ratio and orientation of the $\mathrm{W}$ grains have significant effect on the tendency to the shear band formation. Presumably the ASB initiates at one side, where the direction of the maximum shear stress is approximately parallel to the direction of the major axis of $\mathrm{W}$ grains, and then develops at the other side due to the loss of load-bearing capacity. The ASB has general trends to propagate along the $\mathrm{Ni}-\mathrm{Fe}$ matrix because more energy is needed to shear the $\mathrm{W}$ grains. The influence of the microstructure such as heterogeneity, the content of matrix, and the particle shape on shear band formation is reported $[29,142]$. The quasistatic and dynamic failure of ultrafine grained (UFG $\sim 500 \mathrm{~nm}$ ) tungsten $(\mathrm{W})$ under uniaxial compression is investigated under uniaxial dynamic 


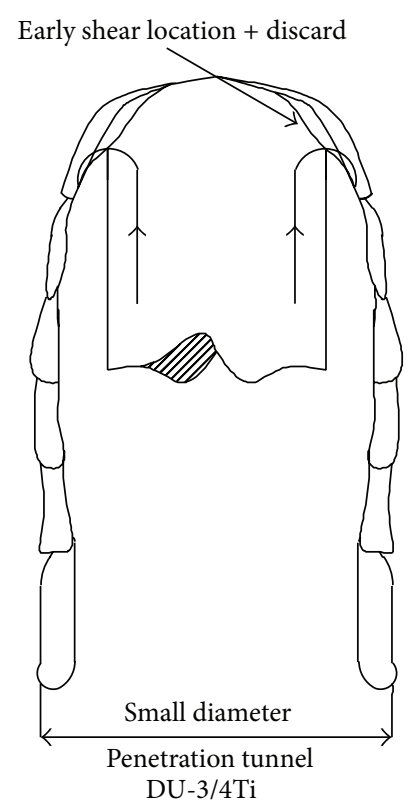

(a)

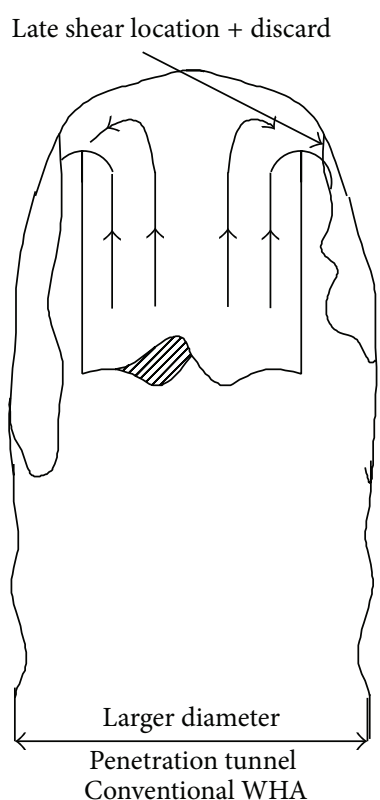

(b)

FIGURE 9: Penetrator deformation behavior of (a) DU rod and (b) WHA rod [135].
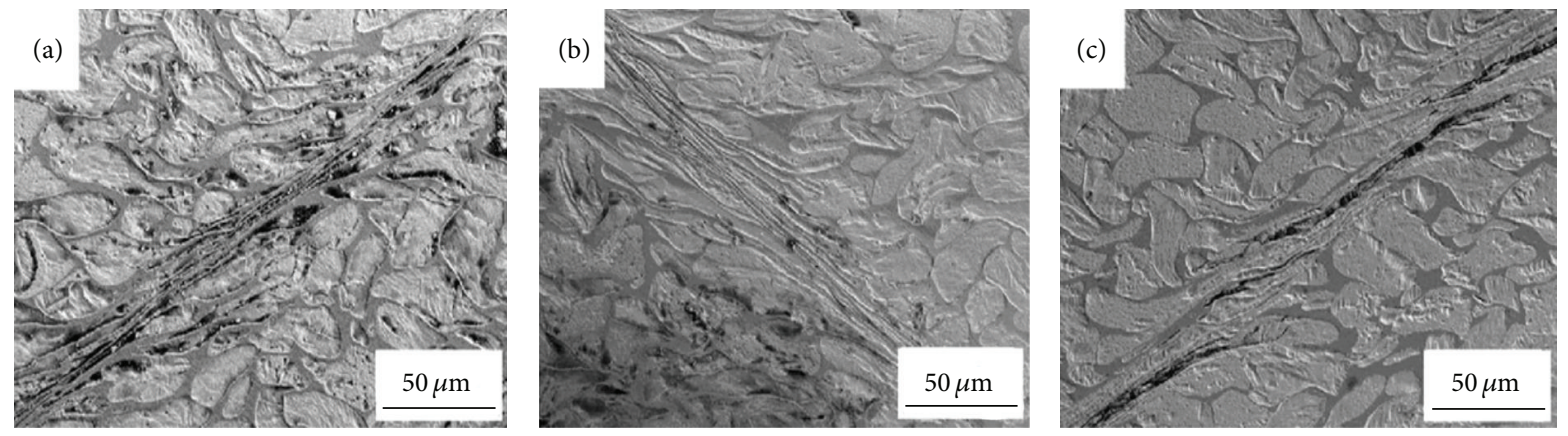

FIGURE 10: SEM micrographs showing ASB of specimens subjected to dynamic compression at initial temperatures of (a) $26^{\circ} \mathrm{C},(\mathrm{b})-20^{\circ} \mathrm{C}$, and (c) $-50^{\circ} \mathrm{C}$, respectively [55].

compression (strain rate $\sim 10^{3} \mathrm{~s}^{-1}$ ) [143]. The true stresstrue strain curves of the UFG-W exhibit significant flow softening, and the peak stress is $\sim 3 \mathrm{GPa}$. The strain rate sensitivity of the UFG-W is reduced to half the value of the conventional W. Furthermore, WHAs rod penetrators processed by hydrostatic extrusion and hot torsion (HE + HT) subjected to ballistic impact maintain an acute shape and show good self-sharping ability, while mushroom-like heads are observed in the as-sintered and as-extruded WHA penetrators [93]. Microstructure analysis shows that ASBs form at the edge of the HE + HT WHA penetrator heads during the penetration and deformed parts of penetrator fall along the ASBs, which are responsible for the good selfsharpening ability and evidently improved the penetration performance (see Figures 10 and 11).

Deformation behavior of W-Ni-Fe alloy by impact loading over a practical range of temperatures ranging from 25 to $1100^{\circ} \mathrm{C}$ and strain rates ranging from $8 \times 10^{2}$ to $4 \times 10^{3} \mathrm{~s}^{-1}$ has been studied by Lee et al. [144]. The flow stress of the composites increases with the strain rate, but an increase in the test temperature has opposite effects. Moreover, work hardening decreases considerably as both the temperature and the strain rate increase. However, a decrease in strain rate sensitivity is observed when the temperature goes above $700^{\circ} \mathrm{C}$. Tensile impact tests performed on a tungsten heavy alloy at strain rates ranging from 100 to $1300 \mathrm{~s}^{-1}$ indicate that strain softening is evidenced [145]. Previous work on pressure-shear plate effects to simple shear under shearing strain rates up to $7 \times 10^{5} \mathrm{~s}^{-1}$ shows that alloys exhibit significant rate sensitivity and thermal softening due to plastic dissipation. Shear bands form when the plastic strains become sufficiently large $[26,146]$. Uranium alloys are better penetrators due to the use of strain onset for shear banding than tungsten alloys, but the assumption that ASB plays a major role in the erosion process of WHAs remains to be verified $[147,148]$. 


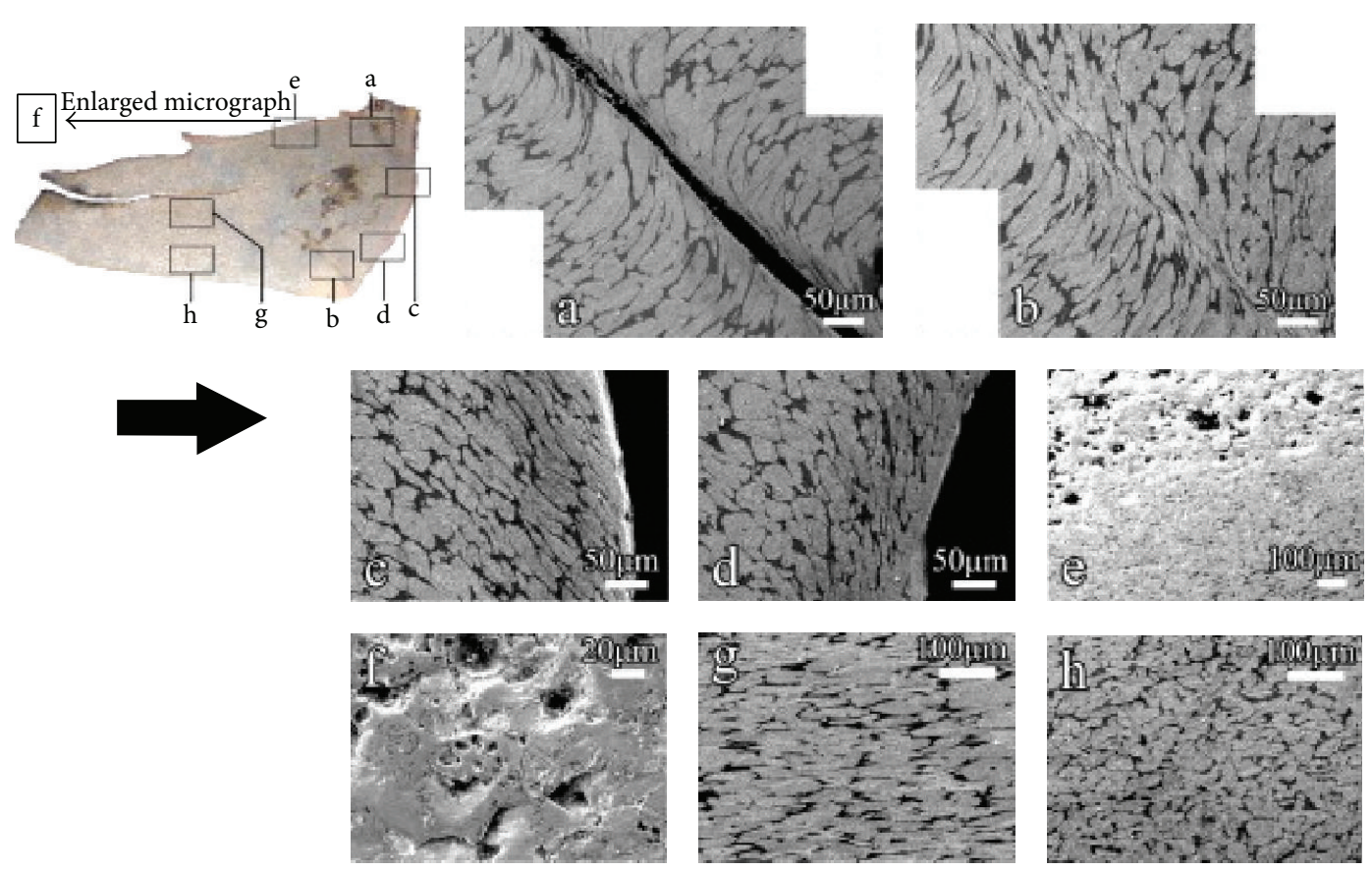

FIGURE 11: SEM micrographs in different regions of the HE + HT WHA penetrator remnant. The arrow depicts penetration direction. (a) Cracks formed along the ASB; (b) obvious localized shearing and microcracks within the ASB; (c) and (d) localized shear bands adjacent to the fracture face indicating that fracture happened along the ASBs; (e) large amounts of holes on one side of the remnant showing micrographs of the central region and the edge field near the tail of the remnant, respectively [93].

Dynamic compression failure testing against steel targets of hardness ranging from 303 to 330 hardness Brinell (HB) is conducted with an impact symmetric Taylor test allowing the quantification of $\mathrm{ABS}$ as a function of the impact velocity [53]. The equivalent failure strains for ABS are identified through numerical simulations of the Taylor tests with a finite element hydrocode implemented with Johnson-Cook constitutive models [25]. These data along with the chiseled nose observations are the first evidences that shear banding is one of the failure processes influencing the penetration performance of conventional WHAs penetrators. The reverse ballistic impact tests on WHAs rods are conducted at a speed of $173 \mathrm{~m} \cdot \mathrm{s}^{-1}$ and $228 \mathrm{~m} \cdot \mathrm{s}^{-1}$ by Dick et al. [149]. The mushroomed end has a slight ellipticity which attribute to radial cracks in the body at low speed while the deformation is more localized along a curved path extending from the mantle near the transition between the mushroomed region and the relatively undeformed rod toward the impact face. A cusp formed in the lateral boundary where the shear band intersects it. Opposite to a point where a shear band is formed, they observe the ductile fracture along a similar path, but no data is obtained for materials properties.

For WHAs, ASB is defined as narrow regions of rapid intense plastic deformation, forming near the transition between the mushroomed region and the relatively undeformed portion of the rod, when its material is either a mixture of Fe-N-W and $\mathrm{W}$ particles or a homogenous alloy $[55,150]$. The ASB is observed under all specimens subjected to various initial temperatures. Figures $10(\mathrm{a}), 10(\mathrm{~b})$, and 10(c) show the SEM micrographs of ASB within specimens subjected to $26^{\circ} \mathrm{C},-20^{\circ} \mathrm{C}$, and $-50^{\circ} \mathrm{C}$, respectively. It can be observed that the as-extruded WHAs exhibit a good susceptibility to ASB even subjected to cryogenic temperatures. Furthermore, with the decrease of initial temperature, the shear strain within ASB shows a decreasing tendency, demonstrating that the initial temperature has some influences on adiabatic shear banding of WHAs. The shear banding in a liquid phase sintered $90 \mathrm{~W}-7 \mathrm{Ni}-3 \mathrm{Fe}$ alloy at $5400 \mathrm{~s}^{-1}$ appeared [129]. Several W-Ni-Fe alloys using compressing Kolsky test at high strain rates for dynamic deformations involving large plastic strains, the response of the WHAs, are controlled by the behavior of $\mathrm{W}$ grains [137]. The overall mechanical properties can be improved when the $\mathrm{W}$ particles are of fine size and the interfacial area between $\mathrm{W}$ particles is reduced [104]. However, penetrators that have too high strength are easily embrittled, and, thus, their penetration performance deteriorates because of fragmentation during penetration. It is desirable for a penetrator to have deformation behavior that can be induced self-sharpening and possess sufficient fracture toughness to minimize fragmentation during high-speed impact [142]. A shear band forms at the point on the rods mantle where the mushroomed region transitions into the straight rod, which agreed qualitatively with Dick et al. [149]. However, the rod is made of either homogeneous tungsten or homogeneous Fe-Ni-W and no such shear band is computed.

Thermomechanical deformations of a WHA rod impacting at normal incidence of a smooth rigid target are modeled based on Fe-Ni-W particles randomly distributed in $\mathrm{W}$ particles, homogenous WHAs, pure tungsten, and pure $\mathrm{Fe}-\mathrm{Ni}$ $\mathrm{W}$ [150]. The role of microstructure on dynamic mechanical 
properties of WHAs has been investigated via constitutive modelling and numerical simulation. An isotropic elastoviscoplastic constitutive model with realistic grain structures to capture shear location in oblique impact (pressure-shear conditions) has used [26] and shows high rate nominally uniform shear deformation [151].

These deformation models and their applications for WHAs rods will be described in the following section.

4.3.1. Formulation. In order to describe dynamic, thermomechanical, and axisymmetric deformations of a cylindrical rod affecting at normal incidence a rigid and planar surface, the Lagrangian or referential description of motion is used. The deformations of rod materials are governed by the following balance laws of mass, linear momentum, moment of momentum, and internal energy.

Equation (4) is the Johnson-Cook relation [25]. The flow stress, $\sigma_{y}$, increases with an increase in the $\epsilon_{p}$ effective plastic strain and the $\epsilon_{p}^{\prime}$ effective plastic strain rate but decreases with an increase in the temperature of a material particle. $C$ is the specific heat, $\theta$ the temperature of a material particle, $\theta_{m}$ its melting temperature, $\theta_{o}$ the room temperature, $T$ the homologous temperature, Se the effective stress $\left(\sigma_{y}\right)$, and $\epsilon_{p}$ the effective plastic strain. In (4), parameters $B$ and $n$ characterize the strain hardening of the material, $C$ and $\epsilon_{o}^{\prime}$ characterize its strain-rate hardening, and $\left(1-T^{m}\right)$ characterizes its thermal softening. For the Taylor impact test, initially, the cylinder rod is stress free, at room temperature $\theta$, and is moving with a uniform speed $V_{o}$ in a direction normal to the plane surface of the target and strikes it at time $t=0$. All bounding surfaces of the rod except that contacting the target are to be taken traction free. No thermal boundary conditions are needed due to the assumption of locally adiabatic deformations:

$$
\begin{aligned}
S_{e}= & \left(A+B\left(\epsilon_{p}\right)^{n}\right) \\
& \times\left(1+C \ln \left(\frac{(2 / 3) \Lambda S_{e}}{\dot{\epsilon}_{o}}\right)\right)\left(1-T^{m}\right) .
\end{aligned}
$$

In physical experiments, fracture in the form of a crack will ensue from the point well before it is heated to its melting temperature. The thermal softening of the WHA they tested is better described by $\left(1-\beta\left(-1+\left(\theta / \theta_{o}\right)^{\alpha}\right)\right)$ where $\alpha$ and $\beta$ are material parameters and for their WHA, $\beta=2.4$ and $\alpha=0.2$ [26]. Its approximate solution is by the finite element method and employs a large-scale explicit code DYNA2D [152] to do so. As the bodies deform, elements near the target/penetrator interface become distorted severely and the time step size drops drastically.

\subsection{Taylor Impact Test Simulations}

4.4.1. The Johnson-Cook Thermal Softening and Zhou et al. Thermal Softening. The following values are assigned to various material and geometric parameters.

Rod length $=60 \mathrm{~mm}$; Rod diameter $=10 \mathrm{~mm} ; V_{o}=$ $150 \mathrm{~m} / \mathrm{s} ; \theta_{o}=293 \mathrm{~K}$.
Depleted Uranium (DU) [153]. $A=1 ; 079 \mathrm{MPa} ; B=1$; $120 \mathrm{MPa} ; C=0.007 ; n=0.25 ; m=1.0 ; \epsilon_{o}^{\prime}=1 / s ; \rho=18$; $600 \mathrm{~kg} / \mathrm{m}^{3} ; \mu=58 \mathrm{GPa} ; K=119 \mathrm{GPa} ; c=117 \mathrm{~J} / \mathrm{kg}^{\circ} \mathrm{C}$, $\theta_{m}=1473 \mathrm{~K}$.

Tungsten Heavy Alloy (WHA). $A=1,506 \mathrm{MPa} ; B=177 \mathrm{MPa}$; $C=0.016 ; n=0.12 ; m=1: 0 ; \epsilon_{o}^{\prime}=1 / s ; \rho=18 ; 600 \mathrm{~kg} / \mathrm{m}^{3}$; $\mu=160 \mathrm{GPa} ; K=328 \mathrm{GPa} ; c=134 \mathrm{~J} / \mathrm{kg}{ }^{\circ} \mathrm{C} ; \theta_{m}=1723 \mathrm{~K}$.

The values of $A, B, C, \theta_{m}, m, \epsilon_{o}^{\prime}$, and $n$ for both materials are taken from Rajendran's report [154] while those of other material parameters are taken from a handbook. It can be noted that the shear modulus for WHA equals 2.76 times that for DU. Computed results for a trial problem indicate that the height of the mushroomed region is approximately $5 \mathrm{~mm}$.

As for Zhou et al. [26] thermal softening, results for the DU and WHA rods with $\beta=2.4$ and $\alpha=0.2$ and 0.3 can be computed, by keeping values of the material and geometric parameters given above. Each one of these values of $\alpha$ gives higher thermal softening than that given by the JohnsonCook relation. Thus, for same values of $\epsilon_{p}$ and $\epsilon_{p}^{\prime}$, the flow stress will be lower with Zhou et al. softening than that with Johnson-Cook relation. It is found that $\alpha=0.2$ and $\beta=2.4$ provided a good fit to the test data for the WHA they used. Here the same values of $\alpha$ for DU are considered because of the lack of data. Thus, the differences for their deformation patterns will be due to the variation in the values of the shear modulus, bulk modulus, and parameters $A, B, C$, and $n$ in (4). It can be noted that the minimum value of the thermal softening function can be taken as zero. The height of the mushroomed region is smaller for $\alpha=0.3$ and it forms sooner in each rod as compared to that for $\alpha=0.2$ [153]. The shapes of the mushroomed regions suggest that severe deformations and hence a shear band may initiate at one or more of the following three locations: adjacent to the stagnation point $(P)$, near the periphery of the impacted end $(Q)$, and close to the inflection point in the curve describing the mantle of the deformed rod $(R)$. Figures 12(a), 12(b), and 12(c) show the deformed meshes of the DU and WHA rods for each of the three thermal softening functions [154]. For $\alpha=0.2$, the aforestated conditions for the initiation of a shear band are satisfied at point $R$ for the WHA rod and the distortions in the deformed mesh confirm the initiation of a shear band there. However, for the DU rod, even though the effective plastic strain at point $R$ grows rapidly first, its rate of growth tapers off. The deformed mesh shown in Figure 12(b) suggests that no shear band initiates from point $R$ since the mesh is regular in the neighborhood of $R$. For each thermal softening considered, the mesh around point $P$ is severely deformed. In addition, the effective stress there drops to less than $80 \%$ of its peak value. Thus, according to the definition of the drop in the effective stress, a shear band initiates at point $P$ for each thermal softening studied.

4.4.2. Rule of Mixture Model. WHA is modeled as a mixture of $10 \% \mathrm{Fe}-\mathrm{Ni}-\mathrm{W}$ particles interspersed randomly in hard tungsten particles. The two are modelled as elastic thermoviscoplastic materials with the flow stress given by (4), but with the Zhou et al. thermal softening and the following values are assigned to different materials $[26,153]$. 

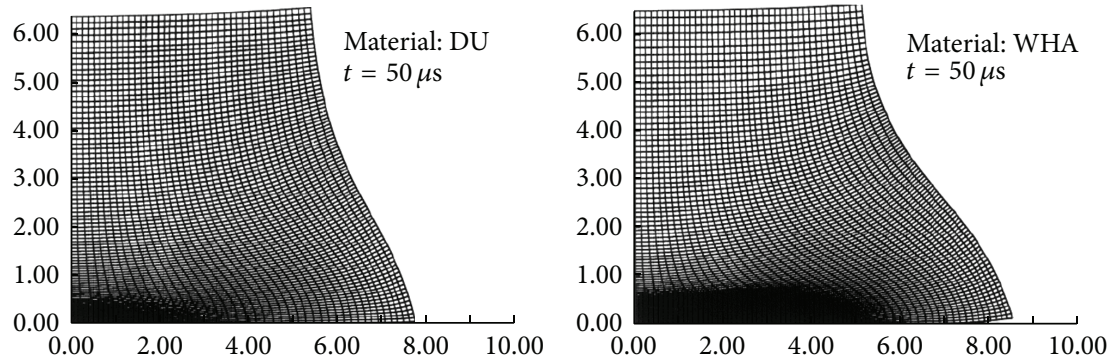

(a)
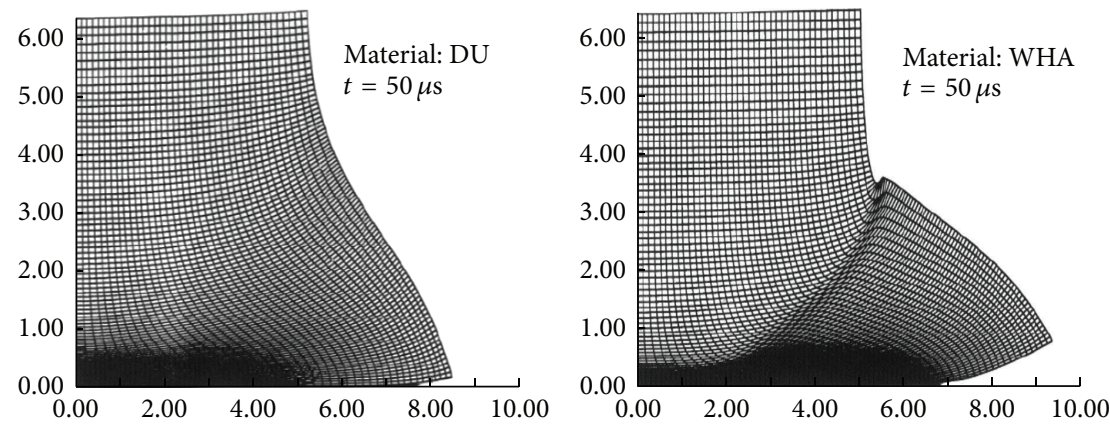

(b)
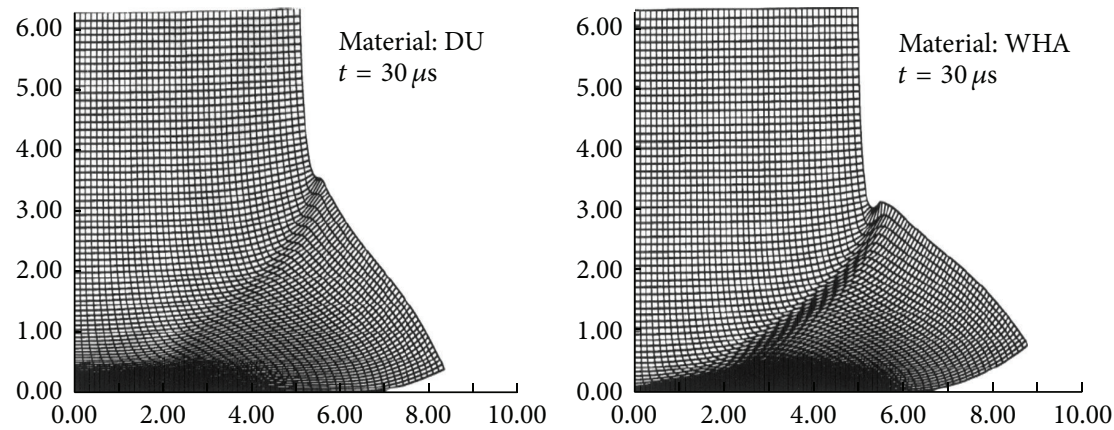

(c)

Figure 12: Deformed meshes of the impacted ends of the DU and WHA rods; (a) Johnson-Cook thermal softening, $m=1.0$; (b) Zhou et al. thermal softening, $\alpha=0.2$; (c) Zhou et al. thermal softening, $\alpha=0.3[25,26,153]$.

Tungsten Particles. $A=730 \mathrm{MPa} B=562 \mathrm{MPa} ; C=0.029 ;$ $n=0.0751 ; K=317 \mathrm{GPa} ; \mu=155 \mathrm{GPa} ; \beta=2.4 ; \alpha=0.15$; $\epsilon_{o}^{\prime}=1.4 \times 10^{-13} / s ; \rho=19300 \mathrm{~kg} / \mathrm{m}^{3} ; c=138 \mathrm{~J} / \mathrm{kg}^{\circ} \mathrm{C}$.

Fe-Ni-W Matrix. $A=150 \mathrm{MPa} B=546 \mathrm{MPa}$; $=0.0838$; $n=0.208 ; K=202.4 \mathrm{GPa} ; \mu=98.84 \mathrm{GPa} ; \beta=2.4 ; \alpha=0.2$; $\epsilon_{o}^{\prime}=6.7 \times 10^{-14} / s ; \rho=9200 \mathrm{~kg} / \mathrm{m}^{3} ; c=382 \mathrm{~J} / \mathrm{kg}^{\circ} \mathrm{C}$.

The diameter and the length of the rod are $6.35 \mathrm{~mm}$ and $25.4 \mathrm{~mm}$, respectively, and simulations of the Taylor impact test are carried out for two impact speeds of 173 and $228 \mathrm{~m} / \mathrm{s}$ [154]. For $V_{o}=173 \mathrm{~m} / \mathrm{s}$, the observed deformation lengths and the geometric mean diameter of the impact face are $22.8 \mathrm{~mm}$ and $9.36 \mathrm{~mm}$, respectively; the corresponding computed values equal $22.25 \mathrm{~mm}$ and $10.72 \mathrm{~mm}$. For $V_{o}=$ $228 \mathrm{~m} / \mathrm{s}$, the computed diameter equals $9.5 \mathrm{~mm}$. The final observed and computed deformed lengths equal $20.9 \mathrm{~mm}$ and $20.5 \mathrm{~mm}$, respectively.
In order to address the effects of crystallographic orientation and dislocation accumulation on the thermomechanical response of WHAs, crystal plasticity based constitutive models have recently been formulated and implemented by some people. The effect of variable ratios of grain and phase boundary strengths on uniaxial tensile failure shows that it is apparent that the variability in spall statistics observed experimentally is due both to the heterogeneous local strengths and flaw distributions and to the multiphase polycrystalline microstructure of the material [154]. Tensile deformation and fracture of realistically rendered [155] and homogenized the microstructures of dual phase tungsten alloys [156]. Numerical results are obtained from a 2D finite element implementation of the crystalline elastoplasticity models for each phase under impact loading. The cohesive laws account for stress state, temperature effects on interfacial strengths, and anisotropic continuum damage mechanics. 
They correlate with the spall strength of the multiphase material [157]. The results indicate the relationships between microstructural features, fracture patterns, and free surface velocity statistics. Statistical variations of free surface velocity are also found to vary with crystal orientation, texture, and temperature dependence of properties controlling the grain boundary fracture [158]. The role of microstructure in the dynamic deformation and fracture of a dual phase, polycrystalline tungsten alloy oriented either perpendicular or parallel to the extrusion direction under high-rate impact loading is investigated via experiments and modeling [159]. Furthermore, finite deformation crystal plasticity theory describes the behavior of the pure tungsten and binder phases, and a stress- and temperature-based cohesive zone model captures fracture at grain and phase boundaries in the microstructure. The results from both experiments and modeling indicate that the grain orientations affect the freesurface velocity profile and spall behavior.

As for the case of Spalling; dynamic tensile failure in uniaxial strain loading, typically referred to as spall or spallation, frequently occurs in impact events, including the current plate impact experiments [160]. The spall strength of a similar variety of WHA to that currently studied has been measured to be 1.7-2.0 GPa [161]. In a typical spall experiment, impact sends a shock wave or elastic and plastic waves, depending on stress level, through both the target and impactor. The initial shocked state was defined by stress and particle velocity. When the compression waves reach the back of the target, a stress-free surface, and the back of the impactor, which has a low-impedance material against it, most of the wave reflects as an unloading wave. This unloading wave from the free surface at the back of the target, also referred to as a rarefaction fan because of its tendency to spread as it propagates, unloads the sample to zero stress and the particle velocity. It can be noted that this free-surface velocity is somewhat lower than the impact velocity. Dandekar [162] attempted to determine the impedance of WHA directly through concurrently backing the target material with void and PMMA. By assuming that the same spall strength is reached in the two cases, the impedance can be found. Instead, the slope (impedance) from the shocked state to the unloaded state in the stress plane can be calculated. It is clear that the pullback velocity varies considerably with position in the sample. The average value of spall strength for the experiment is somewhat larger than the spall strength inferred from the spatially averaged particle velocity. Experimentally, higher velocity impacts yield a somewhat higher spall strength for both orientations. Such behavior has been observed previously in other brittle materials [162]. Post mortem inspection of fully fractured (i.e., spalled) specimens would likely indicate both intergranular and cleavage mechanisms [138]. However, crack propagation and macroscopic spall behavior are thought to require substantial grain cleavage: once sufficiently large, a microcrack initiated along grain/phase boundaries will then propagate fully across the specimen, irrespective of the underlying microstructure. Effective stress near the spall plane can be simulated at different materials and impact velocities but not discussed here. A multiscale descriptive framework for describing effects of micro- or mesostructures on wave propagation in solids under impact loading has been developed [163]. The initiation of spall fracture may be controlled by grain and phase boundaries, in agreement with experimental observations.

\section{Potential Applications of WHAs}

WHAs emerged as the potential candidates for kinetic energy (KE) penetrators in addition to radiation shields and vibration damper applications $[41,65,88,131]$. These alloys are excellent materials for the shielding against gamma rays and hard X-rays due to their combination of radiographic density, machinability, strength, and low toxicity. Counterbalance weights for fixed and rotary wing aircraft have been used for many years because unlike lead, which creeps under its own weight at room temperature. WHAs are routinely used in high density fragmenting devices and armor piercing ammunition ranging from small caliber of $5.56 \mathrm{~mm}$ diameter up to $120 \mathrm{~mm}$ antitank projectiles and beyond. Rotational inertial members are, for example, gyroscope rotors in inertial guidance systems and navigation equipment. WHAs serve as flywheels, the rim components of flywheels, or rotating members in governors. WHAs weight blocks offer up to $50 \%$ more weight in a given volume with added advantages of direct attachment via threaded holes or thru-bolting and the freedom from deformation, which is the constant problem for the lead in addition to hole logging of oil wells.

\section{Concluding Summary}

A review of recent progress on the processing such as conventional powder metallurgy (PM), mechanical alloying (MA), microwave sintering (MWS), and spark-plasma sintering (SPS) methods and microstructure and mechanical properties of WHAs is presented in this paper. Key factors affecting the performance of WHAs are given as follows. Firstly, W and matrix composition, their shape, size of W particles, distributions of $\mathrm{W}$ particles, and pore size are important. Secondly, improvements in strength/stiffness and hardness are observed in most alloy systems with additions of $\mathrm{W}$ in $\mathrm{Fe}-\mathrm{Ni} / \mathrm{Cu}$ alloys. The bonding strength between $\mathrm{W}$ particle and matrix interface is very important in the strengthening of alloys since the load transfer depends on the sufficient bonding between the $\mathrm{W}$ and matrix phase. In addition, optimal sintering temperature and time are important because of the formation of a strong interface between particles and matrix. Moreover, ultimate tensile strength and hardness of WHAs produced by extrusion method enhanced significantly because of the high aspect ratio of the elongated W particles. Thirdly, novel processing technique like SPS provides some advantages over the other methods. The SPS alloyed is found to have higher yield strength than the others, followed by extruded sintered samples. Fourthly, grain refinement is an effective way for improving ductility and strength at ambient temperature with increasing the milling time. Finally, the yield strength of WHAs depends on the microstructural parameters such as tungsten grain size, matrix volume fraction, pore size, and W-W contiguity. Furthermore, the thermal softening in DU and WHA penetrator 
rod are modelled by either the Johnson-Cook relation [25] and that proposed by Zhou et al. [26] or rule of mixtures. The flow stress increases with an increase in the effective plastic strain and effective plastic strain-rate but decreases with a rise in the temperature. The height of the mushroomed region is approximately $5 \mathrm{~mm}$, but the height of the mushroomed region is found to be smaller for $\alpha=0.3$ and it forms sooner in each penetrator rod as compared to that for $\alpha=0.2$ value.

\section{Nomenclature}

\begin{tabular}{|c|c|}
\hline ASB: & Adiabatic shear banding \\
\hline$B:$ & Parameters \\
\hline$C:$ & Specific heat $\left(\mathrm{J} / \mathrm{kg}^{\circ} \mathrm{C}\right)$ \\
\hline CF: & Conventional heating/furnace \\
\hline DU: & Depleted uranium alloys \\
\hline$\epsilon_{p}:$ & Effective plastic strain $(\mathrm{mm} / \mathrm{mm})$ \\
\hline$\epsilon_{p}^{\prime}:$ & $\begin{array}{l}\text { Effective plastic strain with temperature } \\
(\mathrm{mm} / \mathrm{mm})\end{array}$ \\
\hline$C, \epsilon_{0}^{\prime}:$ & Strain-rate hardening \\
\hline$G_{o}:$ & Initial grain size $(\mu \mathrm{m})$ \\
\hline G: & Mean grain size $(\mu \mathrm{m})$ \\
\hline HRA: & Hardness Rockwell A ( Kg/mm²) \\
\hline HB: & Hardness Brinell $\left(\mathrm{Kg} / \mathrm{mm}^{2}\right)$ \\
\hline $\mathrm{HE}+\mathrm{HT}$ WHA: & Hydrostatic extrusion and hot torsion \\
\hline HV 482: & Vickers hardness value $\left(\mathrm{Kg} / \mathrm{mm}^{2}\right)$ \\
\hline$\sigma_{y}:$ & Yield strength $(\mathrm{MPa})$ \\
\hline KE: & Kinetic energy penetrator \\
\hline LPS: & Liquid phase sintering \\
\hline MA: & Mechanical alloying \\
\hline MAed: & Mechanically alloyed \\
\hline MW: & Microwave sintering \\
\hline$n:$ & $\begin{array}{l}\text { Characterize the strain hardening of the } \\
\text { material }\end{array}$ \\
\hline uPIM: & Micropowder injection \\
\hline ODS: & $\begin{array}{l}\text { Oxide dispersion strengthened } \mathrm{Ni} \text { - and } \\
\text { iron base super alloy }\end{array}$ \\
\hline$\Theta:$ & Contact angle $\left({ }^{\circ}\right)$ \\
\hline$\theta_{0}:$ & Room temperature $\left({ }^{\circ} \mathrm{C}\right)$ \\
\hline$\theta_{m}:$ & Melting temperature $\left({ }^{\circ} \mathrm{C}\right)$ \\
\hline UDP: & Ultradispersion particles \\
\hline UFG: & Ultrafine grain $(\sim 500 \mathrm{~nm})$ \\
\hline UTS: & Ultimate tensile strength (MPa) \\
\hline PM: & Powder metallurgy \\
\hline PPS: & Pulse plasma sintering \\
\hline PIM: & Powder injection molding \\
\hline$S_{e}:$ & Effective stress (MPa) \\
\hline SEM: & Scanning electron microscope \\
\hline SPS: & Spark plasma sintering \\
\hline XRD: & $\mathrm{X}$-ray diffraction \\
\hline$\alpha, \beta:$ & Material parameters \\
\hline $\mathrm{Y}_{2} \mathrm{O}_{3}:$ & Yttrium oxide \\
\hline $\mathrm{W}:$ & Tungsten \\
\hline WHAs: & Tungsten heavy alloys \\
\hline W-W: & Tungsten-tungsten grain \\
\hline WC-Co: & Cemented carbides \\
\hline WQ: & Water quenched \\
\hline $1-T^{m}:$ & Thermal softening. \\
\hline
\end{tabular}

\section{Conflict of Interests}

The author declares that there is no conflict of interests regarding the publication of this paper.

\section{Acknowledgments}

The Council of Higher Education (Turkey) supports the author's research. The author also extends his thanks to Associate Professor Alex O. Aning at the Department of Materials Engineering in Virginia Tech \& State University during this study.

\section{References}

[1] J. Reiser, M. Rieth, B. Dafferner, and A. Hoffmann, "Tungsten foil laminate for structural divertor applications-basics and outlook," Journal of Nuclear Materials, vol. 423, no. 1-3, pp. 18, 2012.

[2] M. Greger, L. Čížek, and M. Widomska, "Structure and mechanical properties of formed tungsten based materials," Journal of Materials Processing Technology, vol. 157-158, pp. 683-687, 2004.

[3] S. W. H. Yih and C. T. Wang, Tungsten, Sources, Metallurgy, Properties, and Applications, Plenum Press, New York, NY, USA, 1981.

[4] E. Antolini and E. R. Gonzalez, "Tungsten-based materials for fuel cell applications," Applied Catalysis B: Environmental, vol. 96, no. 3-4, pp. 245-266, 2010.

[5] J. E. Emsley, The Elements, Oxford University Press, New York, NY, USA, 2nd edition, 1991.

[6] X. Gong, J. L. Fan, F. Ding, M. Song, and B. Y. Huang, "Effect of tungsten content on microstructure and quasi-static tensile fracture characteristics of rapidly hot-extruded W-Ni-Fe alloys," International Journal of Refractory Metals and Hard Materials, vol. 30, no. 1, pp. 71-77, 2012.

[7] S. G. Caldwell, “Tungsten heavy alloys," in Powder Metal Technologies and Applications, P. W. Lee and R. Lacocca, Eds., vol. 7, pp. 914-921, ASME Handbook, Materials Park, Ohio, USA, 1998

[8] A. Upadhyaya, "Fabrication of tungsten-copper composites through liquid phase sintering," Transactions of the Indian Institute of Metals, vol. 55, pp. 51-69, 2002.

[9] G. H. S. Price, C. J. Smithells, and S. V. Williams, "Sintered alloys part IA, alloys sintered with a liquid phase present," Journal of the Institute of Metals, vol. 62, pp. 239-264, 1938.

[10] A. I. Prill, "The role of phase relationships in activates sintering of tungsten," Transactions of the AIME, vol. 230, pp. 769-772, 1964.

[11] N. C. Kothari, "Densification and grain growth during liquidphase sintering of tungsten-nickel-copper alloys," Journal of The Less-Common Metals, vol. 13, no. 4, pp. 457-468, 1967.

[12] R. M. German, P. Suri, and S. J. Park, "Review: liquid phase sintering," Journal of Materials Science, vol. 44, no. 1, pp. 1-39, 2009.

[13] K. N. Ramakrishnan and G. S. Upadhayaya, "Effect of composition and sintering on thedensification and mechanical properties," Journal of Materials Science Letters, vol. 9, pp. 456459, 1990.

[14] J. F. Kuzmic, in Modern Development in Powder Metallurgy, H. H. Hausner, Ed., vol. 3, pp. 166-171, Plenum Press, New York, NY, USA, 1996. 
[15] V. Srikanth and G. S. Upadhyaya, "Effect of tungsten particle size on sintered properties of heavy alloys," Powder Technology, vol. 39, no. 1, pp. 61-67, 1984.

[16] A. Sunwoo, S. Groves, D. Goto, and H. Hopkins, "Effect of matrix alloy and cold swaging on micro-tensile properties of tungsten heavy alloys," Materials Letters, vol. 60, no. 3, pp. 321325, 2006.

[17] H. J. Ryu and S. H. Hong, "Fabrication and properties of mechanically alloyed oxide-dispersed tungsten heavy alloys," Materials Science and Engineering A, vol. 363, no. 1-2, pp. 179184, 2003.

[18] S. Park, D.-K. Kim, and S. Lee, "Dynamic deformation behavior of an oxide-dispersed tungsten heavy alloy fabricated by mechanical alloying," Metallurgical and Materials Transactions A: Physical Metallurgy and Materials Science, vol. 32, no. 8, pp. 2011-2020, 2001.

[19] J. X. Liu, S. K. Li, X. Q. Zhou, Z. H. Zhang, H. Y. Zheng, and Y. C. Wang, "Adiabatic shear banding in a tungsten heavy alloy processed by hot-hydrostatic extrusion and hot torsion," Scripta Materialia, vol. 59, no. 12, pp. 1271-1274, 2008.

[20] W. D. Cai, Y. Li, R. J. Dowding, F. A. Mohamed, and E. J. Lavernia, "A review of tungsten-based alloys as kinetic energy penetrator materials," Reviews in Particulate Materials, vol. 3, pp. 71-131, 1995.

[21] L. S. Magnes, in Proceedings of the 4th International Conference on Tungsten, Refractory Metals and Alloys: Processing, Properties and Applications, pp. 41-58, Metal Powder Industries Federation in Cooperation with the Refractory Metals Association and APMI International, Lake Buena Vista, Fla, USA, November 1997.

[22] Z. Zhaohui and W. Fuchi, "Research on the deformation strengthening mechanism of a tungsten heavy alloy by hydrostatic extrusion," International Journal of Refractory Metals and Hard Materials, vol. 19, no. 3, pp. 177-182, 2001.

[23] X. Liu, X. Zhang, S. Yang, C. Zhao, and C. Wang, "Experimental investigation of phase equilibria in the $\mathrm{Co}-\mathrm{W}-\mathrm{Nb}$ ternary system," Intermetallics, vol. 31, pp. 48-54, 2012.

[24] R. M. German, Sintering Theory and Practice, John Wiley \& Sons, New York, NY, USA, 1996.

[25] G. R. Johnson and W. H. Cook, "A constitutive model and data for metals subjected to large strains, high strain rate, and high temperatures," in Proceedings of the 7th International Symposium on Ballistics, pp. 541-548, The Hague, The Netherlands, April 1983.

[26] M. Zhou, A. Needleman, and R. J. Clifton, "Finite element simulations of shear localization in plate impact," Journal of the Mechanics and Physics of Solids, vol. 42, no. 3, pp. 423-458, 1994.

[27] P. C. Angelo and R. Subramanian, Powder Metallurgy: Science, Technology and Applications, Eastern Economy Edition, Prentice-Hall, New Delhi, India, 2008.

[28] W. Liu, Y. Ma, and B. Huang, "Adiabatic shear banding in a tungsten heavy alloy processed by hot-hydrostatic extrusion and hot torsion," Bulletin of Materials Science, vol. 3, pp. 1-6, 2008.

[29] A. Bose and R. M. German, "Matrix composition effects on the tensile properties of tungsten-molybdenum heavy alloys," Metallurgical Transactions A, vol. 21, no. 5, pp. 1325-1327, 1990.

[30] P. B. Kemp and R. M. German, "Grain growth in liquid-phasesintered W-Mo-Ni-Fe alloys," Journal of The Less-Common Metals, vol. 175, no. 2, pp. 353-368, 1991.
[31] K.-H. Lin, C.-S. Hsu, and S.-T. Lin, "Variables on the precipitation of an intermetallic phase for liquid phase sintered W-MoNi-Fe heavy alloys," International Journal of Refractory Metals and Hard Materials, vol. 20, no. 5-6, pp. 401-408, 2002.

[32] T.-Y. Chan and S.-T. Lin, "Microstructural evolution on the sintered properties of W-8 pct Mo-7 pct Ni-3 pct Fe alloy," Journal of Materials Science, vol. 35, no. 15, pp. 3759-3765, 2000.

[33] C. S. Hsu, P. C. Tsai, and S. T. Lin, "Segregation of molibdenim atoms to the liquid-solid interface sintering of W-8\% Mo-7\% Ni-3\% Fe," Metallurgical and Materials Transactions A, vol. 31, pp. 1-7, 2000.

[34] M. Zahrae, H. Arabi, M. T. Salehi, and M. Tamizifar, "Development of a tungsten heavy alloy, W-Ni-Mn, used as kinetic energy penetrator," Iranian Journal of Materials Science and Engineering, vol. 4, no. 3-4, pp. 9-13, 2007.

[35] J. Das, U. R. Kiran, A. Chakraborty, and N. E. Prasad, "Hardness and tensile properties of tungsten based heavy alloys prepared by liquid phase sintering technique," International Journal of Refractory Metals and Hard Materials, vol. 27, no. 3, pp. 577-583, 2009.

[36] J. Das, G. A. Rao, and S. K. Pabi, "Microstructure and mechanical properties of tungsten heavy alloys," Materials Science and Engineering A, vol. 527, no. 29-30, pp. 7841-7847, 2010.

[37] U. R. Kiran, S. Venkat, B. Rishikesh, V. K. Iyer, M. Sankaranarayana, and T. K. Nandy, "Effect of tungsten content on microstructure and mechanical properties of swaged tungsten heavy alloys," Materials Science and Engineering A, vol. 582, pp. 389-396, 2013.

[38] X. Gong, J. L. Fan, F. Ding, M. Song, B. Y. Huang, and J. M. Tian, "Microstructure and highly enhanced mechanical properties of fine-grained tungsten heavy alloy after one-pass rapid hot extrusion," Materials Science and Engineering A, vol. 528, no. 1011, pp. 3646-3652, 2011.

[39] K. R. Sriraman, S. Ganesh Sundara Raman, and S. K. Seshadri, "Synthesis and evaluation of hardness and sliding wear resistance of electrodeposited nanocrystalline Ni-Fe-W alloys," Materials Science and Technology, vol. 22, no. 1, pp. 14-22, 2006.

[40] J. L. Johnson and R. M. German, "Solid-state contributions to densification during liquid-phase sintering," Metallurgical and Materials Transactions B, vol. 27, no. 6, pp. 901-909, 1996.

[41] R. M. German, A. Bose, and S. S. Mani, "Sintering time and atmosphere influences on the microstructure and mechanical properties of tungsten heavy alloys," Metallurgical Transactions A, vol. 23, no. 1, pp. 211-219, 1992.

[42] Y. B. Zhu, Y. Wang, X. Y. Zhang, and G. W. Qin, "W/NiFe phase interfacial characteristics of liquid-phase sintered W-NiFe alloy," International Journal of Refractory Metals and Hard Materials, vol. 25, no. 4, pp. 275-279, 2007.

[43] J. W. Noh, E. P. Kim, H. S. Song, W. H. Baek, K. S. Churn, and S. K. L. Kang, "Matrix penetration of w/w grain," Metallurgical Transactions A, vol. 24, no. 11, pp. 2411-2416, 1993.

[44] Y. Wu, R. M. German, B. Marx, P. Suri, and R. Bollina, "Comparison of densification and distortion behaviors of W$\mathrm{Ni}-\mathrm{Cu}$ and $\mathrm{W}-\mathrm{Ni}-\mathrm{Fe}$ heavy alloys in liquid-phase sintering," Journal of Materials Science, vol. 38, no. 10, pp. 2271-2281, 2003.

[45] P. Lu, X. Xu, W. Yi, and R. M. German, "Porosity effect on densification and shape distortion in liquid phase sintering," Materials Science and Engineering A, vol. 318, no. 1-2, pp. 111-121, 2001.

[46] J. H. Huang, G. A. Zhou, C. Q. Zhu, S. Q. Zhang, and H. Y. Lai, "Influence of pre-alloyed Ni-Fe-Mo binder metal on properties 
and microstructure of tungsten heavy alloys," Materials Letters, vol. 23, no. 1-3, pp. 47-53, 1995.

[47] R. M. German and A. Bose, "Fabrication of intermetallic matrix composites," Materials Science and Engineering A, vol. 107, pp. 107-116, 1989.

[48] D. F. Heaney and R. M. German, "New grain growth concepts in liquid phase sintering," Advances in Powder Metallurgy and Particulate Materials, vol. 3, pp. 303-311, 1994.

[49] P. Lu and R. M. German, "Multiple grain growth events in liquid phase sintering," Journal of Materials Science, vol. 36, no. 14, pp. 3385-3394, 2001.

[50] J. Das, G. Appa Rao, S. K. Pabi, M. Sankaranarayana, and B. Sarma, "Deformation behaviour of a newer tungsten heavy alloy," Materials Science and Engineering A, vol. 528, no. 19-20, pp. 6235-6247, 2011.

[51] R. S. Coates and K. T. Ramesh, "The rate-dependent deformation of a tungsten heavy alloy," Materials Science and Engineering A, vol. 145, no. 2, pp. 159-166, 1991.

[52] Y. Umakoshi, T. Nakano, E. Yanagisawa, T. Takezoe, and A. Negishi, "Effect of alloying elements on anomalous strengthening of $\mathrm{NbSi}_{2}$-based silicides with C40 structure," Materials Science and Engineering A, vol. 239-240, pp. 102-108, 1997.

[53] H. Couque, G. Nicolas, and C. Altmayer, "Relation between shear banding and penetration characteristics of conventional tungsten alloys," International Journal of Impact Engineering, vol. 34, no. 3, pp. 412-423, 2007.

[54] Z. Wei, J. Yu, S. Hu, and Y. Li, "Influence of micro structure on adiabatic shear localization of pre-twisted tungsten heavy alloys," International Journal of Impact Engineering, vol. 24, no. 6-7, pp. 747-758, 2000.

[55] W. Guo, J. Liu, J. Yang, and S. Li, "Effect of initial temperature on dynamic recrystallization of tungsten and matrix within adiabatic shear band of tungsten heavy alloy," Materials Science and Engineering A, vol. 528, no. 19-20, pp. 6248-6252, 2011.

[56] D. Rittel, Z. G. Wang, and M. Merzer, "Adiabatic shear failure and dynamic stored energy of cold work," Physical Review Letters, vol. 96, no. 7, Article ID 075502, 2006.

[57] H. Ye, X. Y. Liu, and H. Hong, "Fabrication of metal matrix composites by metal injection molding-a review," Journal of Materials Processing Technology, vol. 200, no. 1-3, pp. 12-24, 2008.

[58] A. Bose, "Net shaping concepts for tungsten alloys and composites," Powder Metallurgy, vol. 46, no. 2, pp. 121-126, 2003.

[59] N. H. Loh, S. B. Tor, and K. A. Khor, "Production of metal matrix composite part by powder injection molding," Journal of Materials Processing Technology, vol. 108, no. 3, pp. 398-407, 2001.

[60] A. Bose, R. J. Dowding, and G. M. Allen, "Power injection molding of a 95W-4Ni-1Fe alloy," in Powder Injection Molding Symposium, P. H. Booker, J. Gaspervich, and R. M. German, Eds., pp. 261-274, MPIF, Princeton, NJ, USA, 1992.

[61] I. H. Moon, S. S. Ryu, and J. C. Kim, "Sintering behavior of mechanical alloyed W-Cu composite powder," in Proceedings of the 14th International Place Seminar 97, pp. 16-26, Tirol, Austria, May 1997.

[62] Y. S. Zu, Y. H. Chiou, and S. T. Lin, "Performance of powderinjection-molded W-4.9Ni-2.1Fe components," Journal of Materials Engineering and Performance, vol. 5, no. 5, pp. 609-614, 1996.

[63] Y. S. Zu and S. T. Lin, "Optimizing the mechanical properties of injection molded W-4.9\% Ni-2. 1\% Fe in debinding," Journal of Materials Processing Technology, vol. 71, pp. 337-342, 1997.
[64] I. U. Mohsin, C. Gierl, H. Danninger, and M. Momeni, “Thermal de-binding kinetics of injection molded W-8\%Ni-2\%Cu," International Journal of Refractory Metals and Hard Materials, vol. 29, no. 6, pp. 729-732, 2011.

[65] P. Suri, R. M. German, and J. P. de Souza, "Influence of mixing and effect of agglomerates on the green and sintered properties of 97W-2.1Ni-0.9Fe heavy alloys," International Journal of Refractory Metals and Hard Materials, vol. 27, no. 4, pp. 683687, 2009.

[66] J. L. Fan, B. Y. Huang, and X. H. Qu, "Rheologic behavior and sintering characteristic of nanocrystal W-Ni-Fe powder," Journal of Central South University of Technology, vol. 32, no. 1, pp. 66-69, 2001.

[67] J. Fan, B. Huang, and X. Qu, "Distortion prediction and control of injection molded tungsten heavy alloys," Journal of Advanced Materials, vol. 36, no. 1, pp. 72-74, 2004.

[68] B. Huang, J. Fan, S. Liang, and X. Qu, "The rheological and sintering behavior of W-Ni-Fe nano-structured crystalline powder," Journal of Materials Processing Technology, vol. 137, no. 1-3, pp. 177-182, 2003.

[69] Y. M. Li, X. H. Qu, and B. Y. Huang, "Injection molded tungsten heavy alloy," Transactions of Nonferrous Metals Society of China, vol. 8, pp. 576-581, 1998.

[70] A. Bose, G. Jerman, and R. M. German, "Rhenium alloying of tungsten heavy alloys," Powder Metallurgy International, vol. 21, no. 3, pp. 9-13, 1989.

[71] Y. H. Chiou, Y. S. Zu, and S. T. Lin, "Partition of tungsten in the matrix phase for liquid phase sintered $93 \% \mathrm{~W}-4.9 \% \mathrm{Ni}-2.1 \% \mathrm{Fe}$," Scripta Materialia, vol. 34, no. 1, pp. 135-140, 1996.

[72] R. M. German, "Microstructure of the gravitationally settled region in a liquid-phase sintered dilute tungsten heavy alloy," Metallurgical and Materials Transactions A, vol. 26, no. 2, pp. 279-288, 1995.

[73] J. S. Benjamin, "Dispersion strengthened superalloys by mechanical alloying," Metallurgical Transactions, vol. 1, no. 10, pp. 2943-2951, 1970.

[74] C. Suryanarayana, "Mechanical alloying and milling," Progress in Materials Science, vol. 46, no. 1-2, pp. 1-184, 2001.

[75] B. S. Murty and S. Ranganathan, "Novel materials synthesis by mechanicalalloying/milling," International Materials Reviews, vol. 43, no. 3, pp. 101-106, 1998.

[76] H. J. Ryu, S. H. Hong, and W. H. Baek, "Microstructure and mechanical properties of mechanically alloyed and solid-state sintered tungsten heavy alloys," Materials Science and Engineering A, vol. 291, no. 1-2, pp. 91-96, 2000.

[77] K. H. Lee, S. I. Cha, H. J. Ryu, and S. H. Hong, "Effect of two-stage sintering process on microstructure and mechanical properties of ODS tungsten heavy alloy," Materials Science and Engineering A, vol. 458, no. 1-2, pp. 323-329, 2007.

[78] S. H. Hong and H. J. Ryu, "Combination of mechanical alloying and two-stage sintering of a $93 \mathrm{~W}-5.6 \mathrm{Ni}-1.4 \mathrm{Fe}$ tungsten heavy alloy," Materials Science and Engineering A, vol. 344, no. 1-2, pp. 253-260, 2003.

[79] K. H. Lee, S. I. Cha, H. J. Ryu, and S. H. Hong, "ffect of sintering process on microstructure and mechanical properties of ODS tungsten heavy alloy," Materials Science and Engineering A, vol. 452-453, pp. 55-60, 2007.

[80] J.-W. Yan, Y. Liu, A.-F. Peng, and Q.-G. Lu, "Fabrication of nano-crystalline $\mathrm{W}-\mathrm{Ni}-\mathrm{Fe}$ pre-alloyed powders by mechanical alloying technique," Transactions of Nonferrous Metals Society of China (English Edition), vol. 19, no. 3, pp. s711-s717, 2009. 
[81] D. P. Xiang, L. Ding, Y. Y. Li, J. B. Li, X. Q. Li, and C. $\mathrm{Li}$, "Microstructure and mechanical properties of fine-grained W-7Ni-3Fe heavy alloy by spark plasma sintering," Materials Science and Engineering A, vol. 551, pp. 95-99, 2012.

[82] Z. W. Zhang, J. E. Zhou, S. Q. Xi, G. Ran, and P. L. Li, "Amorphization and thermal stability of mechanical alloyed WNi-Fe," Materials Science and Engineering A, vol. A410, pp. 3439, 2006.

[83] F. Jing-Lian, L. Tao, C. Hui-Chao, and W. Deng-Long, "Preparation of fine grain tungsten heavy alloy with high properties by mechanical alloying and yttrium oxide addition," Journal of Materials Processing Technology, vol. 208, no. 1-3, pp. 463-469, 2008.

[84] J. Fan, B. Huang, X. Qu, and K. A. Khalil, "MIM of mechanically alloyed nanoscale W-Ni-Fe powder," International Journal of Powder Metallurgy, vol. 38, no. 6, pp. 56-61, 2002.

[85] J. S. C. Jang, J. C. Fwu, L. J. Chang, G. J. Chen, and C. T. Hsu, "Study on the solid-phase sintering of the nano-structured heavy tungsten alloy powder," Journal of Alloys and Compounds, vol. 434-435, pp. 367-370, 2007.

[86] E. P. Kim, M. H. Hong, W. H. Baek, and I. H. Moon, “The effect of manganese addition on the microstructure of W-Ni-Fe heavy alloy," Metallurgical and Materials Transactions A, vol. 30, pp. 627-632, 1999.

[87] P. Suri, S. V. Atre, R. M. German, and J. P. de Souza, "Effect of mixing on the rheology and particle characteristics of tungstenbased powder injection molding feedstock," Materials Science and Engineering A, vol. 356, no. 1-2, pp. 337-344, 2003.

[88] J. L. Fan, X. Gong, B. Y. Huang, M. Song, T. Liu, and J. M. Tian, "Densification behavior of nanocrystalline W-Ni-Fe composite powders prepared by sol-spray drying and hydrogen reduction process," Journal of Alloys and Compounds, vol. 489, no. 1, pp. 188-194, 2010.

[89] B. Katavic and Z. Odanoic, "Effects of strain aging on the structure and mechanical properties of PM $92 \cdot 5 \mathrm{~W}-5 \mathrm{Ni}-2 \cdot 5 \mathrm{Fe}$ heavy alloys," Powder Metallurgy, vol. 48, no. 3, pp. 288-294, 2005.

[90] U. Ravi Kiran, A. Sambasiva Rao, M. Sankaranarayana, and T. K. Nandy, "Swaging and heat treatment studies on sintered $90 \mathrm{~W}-6 \mathrm{Ni}-2 \mathrm{Fe}-2 \mathrm{Co}$ tungsten heavy alloy," International Journal of Refractory Metals and Hard Materials, vol. 33, pp. 113-121, 2012.

[91] G. R. Goren-Muginstein and A. Rosen, "The effect of cold deformation on grain refinement of heavy metals," Materials Science and Engineering A, vol. 238, no. 2, pp. 351-356, 1997.

[92] Y. Yang, H. Lianxi, and W. Erde, "Microstructure and mechanical properties of a hot-hydrostatically extruded $93 \mathrm{~W}-4.9 \mathrm{Ni}-$ 2.1Fe alloy," Materials Science and Engineering A, vol. 435-436, pp. 620-624, 2006.

[93] Z. Xiaoqing, L. Shukui, L. Jinxu, W. Yingchun, and W. Xing, "Self-sharpening behavior during ballistic impact of the tungsten heavy alloy rod penetrators processed by hot-hydrostatic extrusion and hot torsion," Materials Science and Engineering A, vol. 527, no. 18-19, pp. 4881-4886, 2010.

[94] G. Bao and K. T. Ramesh, "Plastic flow of a tungsten-based composite under quasi-static compression," Acta Metallurgica Et Materialia, vol. 41, no. 9, pp. 2711-2719, 1993.

[95] Z. Xie, J. Yang, X. Huang, and Y. Huang, "Microwave processing and properties of ceramics with different dielectric loss," Journal of the European Ceramic Society, vol. 19, no. 3, pp. 381-387, 1999.
[96] M. Oghbaei and O. Mirzaee, "Microwave versus conventional sintering: a review of fundamentals, advantages and applications," Journal of Alloys and Compounds, vol. 494, no. 1-2, pp. 175-189, 2010.

[97] A. Upadhyaya, S. K. Tiwari, and P. Mishra, "Microwave sintering of W-Ni-Fe alloy," Scripta Materialia, vol. 56, no. 1, pp. 5-8, 2007.

[98] C. Zhou, J. Yi, S. Luo, Y. Peng, L. Li, and G. Chen, "Effect of heating rate on the microwave sintered W-Ni-Fe heavy alloys," Journal of Alloys and Compounds, vol. 482, no. 1-2, pp. L6-L8, 2009.

[99] A. Mondal, A. Upadhyaya, and D. Agrawal, "Microwave and conventional sintering of $90 \mathrm{~W}-7 \mathrm{Ni}-3 \mathrm{Cu}$ alloys with premixed and prealloyed binder phase," Materials Science and Engineering $A$, vol. 527, no. 26, pp. 6870-6878, 2010.

[100] M. Yan and J. Hu, "Microwave sintering of high-permeability $\left(\mathrm{Ni}_{0.20} \mathrm{Zn}_{0.60} \mathrm{Cu}_{0.20}\right) \mathrm{Fe}_{1.98} \mathrm{O}_{4}$ ferrite at low sintering temperatures," Journal of Magnetism and Magnetic Materials, vol. 305, no. 1, pp. 171-176, 2006.

[101] Z. A. Munir, U. Anselmi-Tamburini, and M. Ohyanagi, "The effect of electric field and pressure on the synthesis and consolidation of materials: a review of the spark plasma sintering method," Journal of Materials Science, vol. 41, no. 3, pp. 763-777, 2006.

[102] R. Orru, R. Licheri, A. M. Locci, A. Cincotti, and G. Cao, "Consolidation/synthesis of materials by electric current activated/assisted sintering," Materials Science and Engineering R: Reports, vol. 63, no. 4-6, pp. 127-287, 2009.

[103] Z.-W. Zhang, J.-E. Zhou, S.-Q. Xi, G. Ran, and P.-L. Li, "Phase transformation and thermal stability of mechanically alloyed W-Ni-Fe composite materials," Materials Science and Engineering A, vol. 379, no. 1-2, pp. 148-153, 2004.

[104] V. N. Chuvil'deev, A. V. Nokhrin, G. V. Baranov et al., "Study of the structure and mechanical properties of nano- and ultradispersed mechanically activated heavy tungsten alloys," Nanotechnologies in Russia, vol. 8, no. 1-2, pp. 108-121, 2013.

[105] Y. Li, K. Hu, X. Li, X. Ai, and S. Qu, "Fine-grained 93W-5.6Ni$1.4 \mathrm{Fe}$ heavy alloys with enhanced performance prepared by spark plasma sintering," Materials Science and Engineering A, vol. 573, pp. 245-252, 2013.

[106] B. H. Rabin and R. M. German, "Microstructure effects on tensile properties of tungsten-Nickel-Iron composites," Metallurgical Transactions A, vol. 19, no. 6, pp. 1523-1532, 1988.

[107] J. D. Clayton, "Continuum multiscale modeling of finite deformation plasticity and anisotropic damage in polycrystals," Theoretical and Applied Fracture Mechanics, vol. 45, no. 3, pp. 163$185,2006$.

[108] X. Q. Li, H. W. Xin, K. Hu, and Y. Y. Li, "Microstructure and properties of ultra-fine tungsten heavy alloys prepared by mechanical alloying and electric current activated sintering," Transactions of Nonferrous Metals Society of China, vol. 20, no. 3, pp. 443-449, 2010.

[109] K. Hu, X. Li, D. Zheng, and Y. Li, "SPS densification behavior of W-5.6Ni-1.4Fe heavy alloy powders," Rare Metals, vol. 30, no. 1, pp. 581-587, 2011.

[110] K. Hu, X. Li, S. Qu, and Y. Li, "Spark-Plasma Sintering of W5.6Ni-1.4Fe Heavy Alloys: Densification and Grain Growth," Metallurgical and Materials Transactions A: Physical Metallurgy and Materials Science, vol. 44, no. 2, pp. 923-933, 2013.

[111] K. Vanmeensel, A. Laptev, J. Hennicke, J. Vleugels, and O. van der Biest, "Modelling of the temperature distribution during 
field assisted sintering," Acta Materialia, vol. 53, no. 16, pp. 4379-4388, 2005.

[112] D. Salamon, M. Eriksson, M. Nygren, and Z. Shen, "Can the use of pulsed direct current induce oscillation in the applied pressure during spark plasma sintering?" Science and Technology of Advanced Materials, vol. 13, no. 1, Article ID 015005, 2012.

[113] Y. Liu and R. M. German, "Contact angle and solid-liquid-vapor equilibrium," Acta Materialia, vol. 44, no. 4, pp. 1657-1663, 1996.

[114] J. Zhu, S. Cao, and H. Liu, "Fabrication of W-Ni-Fe alloys with gradient structures," International Journal of Refractory Metals and Hard Materials, vol. 36, pp. 72-75, 2013.

[115] R. Gero, L. Borukhin, and I. Pikus, "Some structural effects of plastic deformation on tungsten heavy metal alloys," Materials Science and Engineering A, vol. 302, no. 1, pp. 162-167, 2001.

[116] R. M. German, Liquid Phase Sintering, Plenum Press, New York, NY, USA, 1985.

[117] R. Bollina and R. M. German, "Heating rate effects on microstructural properties of liquid phase sintered tungsten heavy alloys," International Journal of Refractory Metals and Hard Materials, vol. 22, no. 2-3, pp. 117-122, 2004.

[118] D. V. Edmonds, "Structure/property relationships in sintered heavy alloys," International Journal of Refractory Metals and Hard Materials, vol. 10, no. 1, pp. 15-26, 1991.

[119] H. Liu, S. Cao, J. Zhu, Y. Jin, and B. Chen, "Densification, microstructure and mechanical properties of $90 \mathrm{~W}-4 \mathrm{Ni}-6 \mathrm{Mn}$ heavy alloy," International Journal of Refractory Metals and Hard Materials, vol. 37, pp. 121-126, 2013.

[120] F. Wakai, M. Yoshida, Y. Shinoda, and T. Akatsu, "Coarsening and grain growth in sintering of two particles of different sizes," Acta Materialia, vol. 53, no. 5, pp. 1361-1371, 2005.

[121] T.-K. Kang and D. N. Yoon, "Coarsening of tungsten grains in liquid nickel-tungsten matrix," Metallurgical Transactions A, vol. 9, no. 3, pp. 433-438, 1978.

[122] U. R. Kiran, A. Panchal, M. Sankaranarayana, and T. K. Nandy, "Tensile and impact behavior of swaged tungsten heavy alloys processed by liquid phase sintering," International Journal of Refractory Metals and Hard Materials, vol. 37, pp. 1-11, 2013.

[123] O. J. Kwon and D. N. Yoon, "Closure of isolated pores in liquid phase sintering of W-Ni," The International Journal of Powder Metallurgy \& Powder Technology, vol. 17, no. 2, pp. 127-131, 1981.

[124] D. J. Lee and R. M. German, "Sintering behavior of ironaluminium powder mixes," International Journal of Powder Metallurgy and Powder Technology, vol. 21, pp. 9-14, 1985.

[125] S.-M. Lee and S.-J. L. Kang, "Theoretical analysis of liquid-phase sintering: pore filling theory," Acta Materialia, vol. 46, no. 9, pp. 3191-3202, 1998.

[126] J. Langer, M. J. Hoffmann, and O. Guillon, "Electric fieldassisted sintering and hot pressing of semiconductive zinc oxide: a comparative study," Journal of the American Ceramic Society, vol. 94, no. 8, pp. 2344-2353, 2011.

[127] D. Demirskyi, H. Borodianska, D. Agrawal, A. Ragulya, Y. Sakka, and O. Vasylkiv, "Peculiarities of the neck growth process during initial stage of spark-plasma, microwave and conventional sintering of WC spheres," Journal of Alloys and Compounds, vol. 523, pp. 1-10, 2012.

[128] K. Wang, Z. Fu, W. Wang, Y. Wang, J. Zhang, and Q. Zhang, "Study on fabrication and mechanism in of porous metals by spark plasma sintering," Journal of Materials Science, vol. 42, pp. 302-307, 2007.

[129] J. Lankford, H. Couque, A. Bose, and R. German, "Dynamic deformation and failure of tungsten heavy alloys," in Proceedings of the TMS Annual Meeting on Recent Advances in Tungsten and Tungsten Alloys, pp. 151-160, Warrendale, Pa, USA, February 1991.

[130] Y. Şahin, Introduction to Composite Materials, Seçkin Publication, Ankara, Turkey, 2nd edition, 2006.

[131] F. Akhtar, "An investigation on the solid state sintering of mechanically alloyed nano-structured 90W-Ni-Fe tungsten heavy alloy," International Journal of Refractory Metals and Hard Materials, vol. 26, no. 3, pp. 145-151, 2008.

[132] I. S. Humail, F. Akhtar, S. J. Askari, M. Tufail, and X. Qu, “Tensile behavior change depending on the varying tungsten content of W-Ni-Fe alloys," International Journal of Refractory Metals and Hard Materials, vol. 25, no. 5-6, pp. 380-385, 2007.

[133] X. Gong, J. L. Fan, B. Y. Huang, and J. M. Tian, "Microstructure characteristics and a deformation mechanism of fine-grained tungsten heavy alloy under high strain rate compression," Materials Science and Engineering A, vol. 527, no. 29-30, pp. 75657570, 2010.

[134] Y. Yu, L. Hu, and E. Wang, "Microstructure and mechanical properties of a hot-hydrostatically extruded $93 \mathrm{~W}-4.9 \mathrm{Ni}-2.1 \mathrm{Fe}$ alloy," Materials Science and Engineering A, vol. 435-436, pp. 620-624, 2006.

[135] A. Upadhyaya, "Processing strategy for consolidating tungsten heavy alloys for ordnance applications," Materials Chemistry and Physics, vol. 67, no. 1-3, pp. 101-110, 2001.

[136] L. S. Magness Jr., "High strain rate deformation behaviors of kinetic energy penetrator materials during ballistic impact," Mechanics of Materials, vol. 17, no. 2-3, pp. 147-154, 1994.

[137] K. T. Ramesh and R. S. Coates, "Microstructural influences on the dynamic response of tungsten heavy alloys," Metallurgical Transactions A, vol. 23, no. 9, pp. 2625-2630, 1992.

[138] S. Bless and R. Chau, "Tensile failure of tungsten rods," in Shock Compression of Condensed Matter, M. D. Furnish, M. Elert, T. P. Russell, and C. T. White, Eds., pp. 603-606, American Institute of Physics, New York, NY, USA, 2006.

[139] D. P. Dandekar and W. J. Weisgerber, "Shock response of a heavy tungsten alloy," International Journal of Plasticity, vol. 15, no. 12, pp. 1291-1309, 1999.

[140] J. C. F. Millett, N. K. Bourne, Z. Rosenberg, and J. E. Field, "Shear strength measurements in a tungsten alloy during shock loading," Journal of Applied Physics, vol. 86, no. 12, pp. 67076709, 1999.

[141] M. Zhou and R. J. Clifton, "Dynamic constitutive and failure behavior of a two-phase tungsten composite," Journal of Applied Mechanics, Transactions ASME, vol. 64, no. 3, pp. 487-494, 1997.

[142] D.-K. Kim, S. Lee, and H.-S. Song, "Effect of tungsten particle shape on dynamic deformation and fracture behavior of tungsten heavy alloys," Metallurgical and Materials Transactions A, vol. 29, no. 3, pp. 1057-1069, 1998.

[143] Q. Wei, T. Jiao, K. T. Ramesh et al., "Mechanical behavior and dynamic failure of high-strength ultrafine grained tungsten under uniaxial compression," Acta Materialia, vol. 54, no. 1, pp. 77-87, 2006.

[144] W.-S. Lee, G.-L. Xiea, and C.-F. Lin, “The strain rate and temperature dependence of the dynamic impact response of tungsten composite," Materials Science and Engineering A, vol. 257, no. 2, pp. 256-267, 1998.

[145] Y. Zhou, Y. Wang, P. K. Mallick, and Y. Xia, "Strain softening constitutive equation for tungsten heavy alloy under tensile impact," Materials Letters, vol. 58, no. 22-23, pp. 2725-2729, 2004. 
[146] M. Zhou, R. J. Clifton, and A. Needleman, "Shear band formation in a W-Ni-Fe heavy alloy under plate impact," in Tungsten \& Tungsten Alloys, pp. 343-356, Metal Powder Industries Federation, Arlington, Va, USA, 1992.

[147] H. Couque Jr., J. Lankford, and A. Bose, "Tensile fracture and shear location under high loading rate in tungsten alloys," Journal de Physique III, vol. 2, pp. 2225-2229, 1992.

[148] S. Yadav and T. Ramesh, "Strain rate properties of tungsten based composites," Materials Science and Engineering A, vol. 203, pp. 9140-9153, 1995.

[149] R. D. Dick, V. Ramachandran, J. D. Williams, R. W. Armstrong, W. H. Holt, and W. Mock Jr., "Dynamic deformation of $\mathrm{W}_{7} \mathrm{Ni}_{3} \mathrm{Fe}$ alloy via reverse-ballistic impact," in Tungsten and Tungsten Alloys-Recent Advances, A. Crowson and E. S. Chen, Eds., pp. 269-276, The Minerals, Metals and Materails Society, 1991.

[150] J. B. Stevens and R. C. Batra, "Adiabatic shear bands in the taylor impact test for a WHA rod," International Journal of Plasticity, vol. 14, no. 9, pp. 841-854, 1998.

[151] M. Zhou, "The growth of shear bands in composite microstructures," International Journal of Plasticity, vol. 14, no. 8, pp. 733754, 1998.

[152] R. G. Whirley, B. E. Engelmann, and J. O. Hallquist, "DYNA2D, a nonlinear, explicit, two-dimensional finite element code for solid mechanics, user manual," Lawrence Livermore National Laboratory Report UCRL-MA-110630, 1992.

[153] A. M. Rajendran, "High strain rate behavior of metals, ceramics, and concrete," Tech. Rep. WL-TR-92-4006, Wright Patterson Air Force Base, Wright-Patterson Air Force Base, Ohio, USA, 1992.

[154] J. B. Stevens, Finite element analysis of adiabatic shearbands in impact and penetration problems [M.S. thesis], Virginia Polytechnic Institute and State University, Blacksburg, Va, USA, 1996.

[155] J. D. Clayton, "Dynamic plasticity and fracture in high density polycrystals: constitutive modeling and numerical simulation," Journal of the Mechanics and Physics of Solids, vol. 53, no. 2, pp. 261-301, 2005.

[156] J. D. Clayton, "Continuum multiscale modeling of finite deformation plasticity and anisotropic damage in polycrystals," Theoretical and Applied Fracture Mechanics, vol. 45, no. 3, pp. 163-185, 2006.

[157] J. D. Clayton, "Modeling dynamic plasticity and spall fracture in high density polycrystalline alloys," International Journal of Solids and Structures, vol. 42, no. 16-17, pp. 4613-4640, 2005.

[158] J. D. Clayton, "Plasticity and spall in high density polycrystals: modeling and simulation," in Compression of Condensed Matter, M. D. Furnish, M. Elert, T. P. Russell, and C. T. White, Eds., pp. 311-314, American Institute of Physics, New York, NY, USA, 2006.

[159] T. J. Vogler and J. D. Clayton, "Heterogeneous deformation and spall of an extruded tungsten alloy: plate impact experiments and crystal plasticity modeling," Journal of the Mechanics and Physics of Solids, vol. 56, no. 2, pp. 297-335, 2008.

[160] T. H. Antoun, L. Seaman, D. R. Curran, G. I. Kanel, S. V. Razorenov, and A. V. Utkin, Spall Fracture, Springer, New York, NY, USA, 2003.

[161] D. P. Dandekar and W. J. Weisgerber, "Shock response of a heavy tungsten alloy," International journal of plasticity, vol. 15, no. 12, pp. 1291-1309, 1999.

[162] D. P. Dandekar, "Spall strength of silicon carbide under normal and simultaneous compression-shear shock wave loading,"
International Journal of Applied Ceramic Technology, vol. 1, no. 2, pp. 261-268, 2004.

[163] Y. I. Mescheryakov, "Meso-macro energy exchange in shock deformed and fractured solids," in High-Pressure Shock Compression of Solids VI: Old Paradigms and New Challenges, Y. Horie, L. Davison, and N. N. Thadhani, Eds., pp. 169-213, Springer, New York, NY, USA, 2003. 

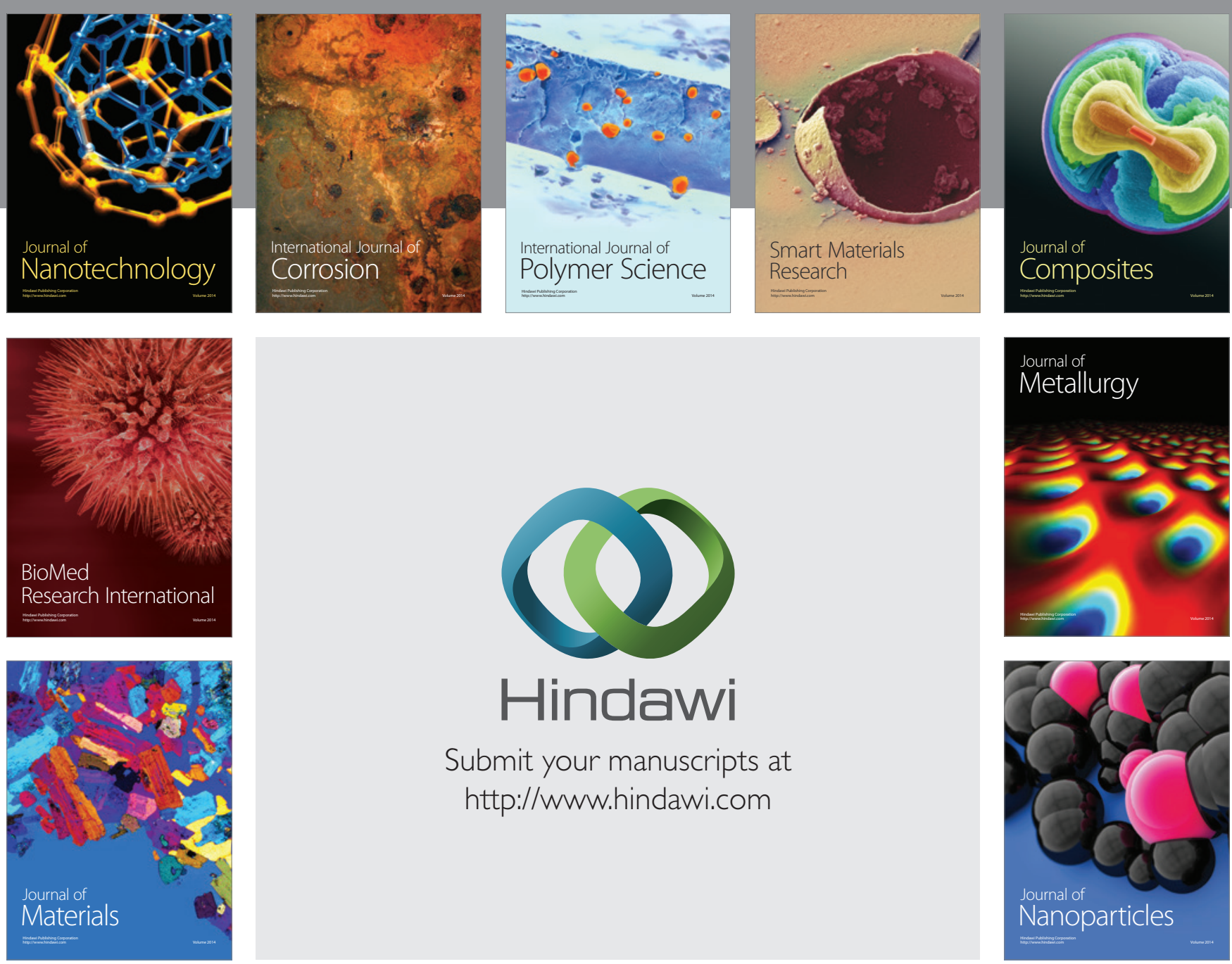

Submit your manuscripts at http://www.hindawi.com
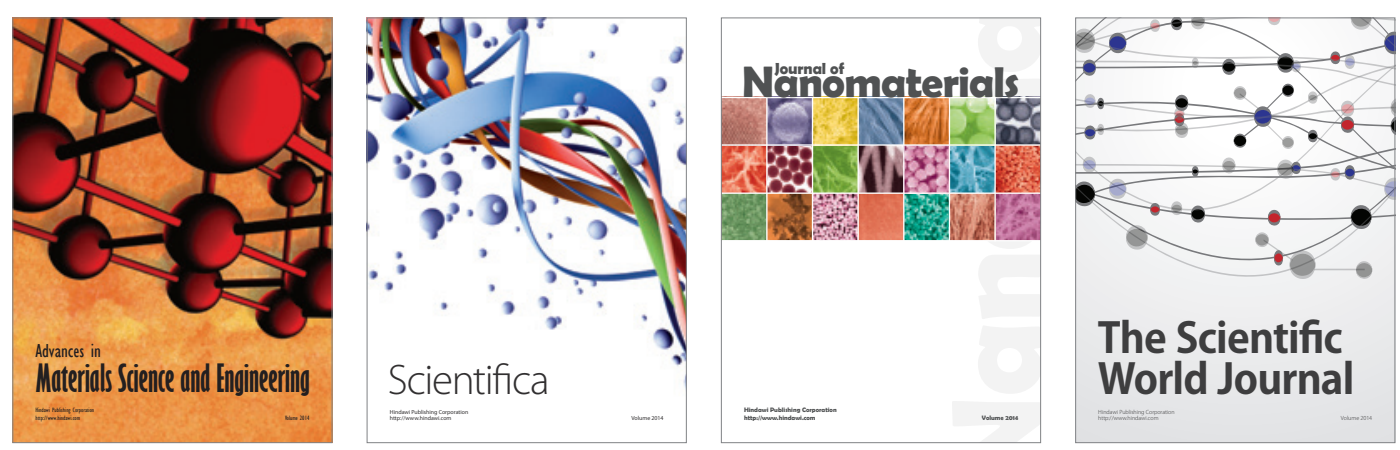

\section{The Scientific World Journal}
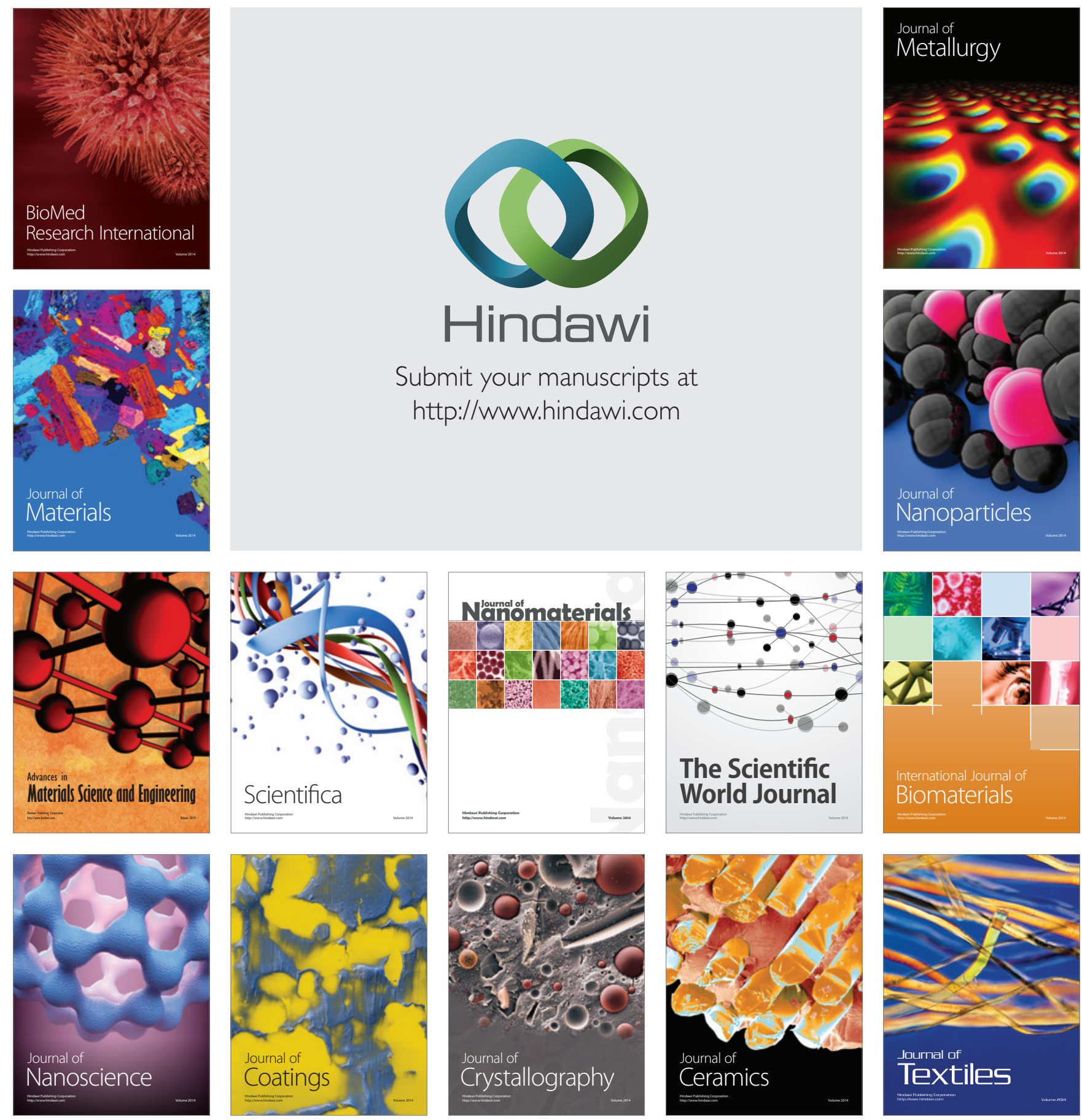